\title{
Review of The Logic of Conventional Implicatures by Chris Potts
}

\author{
Patricia Amaral, Craige Roberts and E. Allyn Smith ${ }^{1}$ \\ The Ohio State University
}

The term 'conventional implicature' was introduced by Grice (1967/1975), though the notion had been foreshadowed as early as Grice (1961). In the central passages, he says (1967/1989:24-26):

I wish to introduce, as terms of art, the verb implicate and the related nouns implicature (cf. implying) and implicatum (cf. what is implied). ...

In some cases the conventional meaning of the words used will determine what is implicated, besides helping to determine what is said. If I say (smugly), He is an Englishman; he is, therefore, brave, I have certainly committed myself, by virtue of the meaning of my words, to its being the case that his being brave is a consequence of (follows from) his being an Englishman. But while I have said that he is an Englishman, and said that he is brave, I do not want to say that I have said (in the favored sense) that it follows from his being an Englishman that he is brave, though I have certainly indicated, and so implicated, that this is so. I do not want to say that my utterance of this sentence would be, strictly speaking, false should the consequence in question fail to hold. So some implicatures are conventional...

The only other English expression that Grice identified as triggering a conventional implicature was but.

The term has been used in various ways by different authors. For example, Karttunen \& Peters (1979) used it to describe conventionally triggered presuppositions. Bach (1999) argued that Grice was wrong about but and therefore, calling into question the existence of conventional implicatures as a class. But Chris Potts puts quite a different complexion on the matter in the present book, a revision of his 2003 Ph.D. dissertation in Linguistics at the University of California at Santa Cruz. He agrees with Grice that conventional implicatures (hereafter, CIs) are a conventionally triggered commitment of the speaker, while logically independent of what is said. But he also agrees with Bach that Grice's two examples are not CIs. Instead, Potts identifies a broad new class of CI triggers and offers a detailed, formal theory of how they contribute to the meaning of an utterance in which they occur. The work has already had a broad impact on semantics, and is sure to have a lasting influence.

Accordingly, we think both the notion of conventional implicature and Potts' characterization of it deserve careful scrutiny. The fragment he develops is intended to yield a compositional interpretation for a fairly standard generative grammar, and hence has the virtue of making clear predictions about the meanings of a range of utterances involving CIs.

\footnotetext{
${ }^{1}$ The authors' names are listed alphabetically; all work was fully joint. We would like to thank Chris Potts for extensive discussions and correspondence about the material discussed here, and David Dowty, Yusuke Kubota and Judith Tonhauser for important discussions and comments on an earlier draft. We would also like to thank our two excellent anonymous $L \& P$ reviewers. Of course, all opinions expressed here are those of the authors.
} 
In this review, we have two central aims: First, to explore some of the empirical predictions of Potts' theory, in order to assess its descriptive adequacy. Second, to consider how it fares as an explanatory theory, one that enlightens us about what a CI is and why it behaves the way it does.

With respect to the descriptive adequacy of the theory, we agree with Potts that the semantic content of CIs is relatively independent of what he calls the at-issue content of an utteranceroughly, the remainder of its non-presuppositional conventionally conveyed meaning. But crucially, CI and at-issue content are not entirely independent of each other. We also show that the class of elements that Potts claims trigger CIs appears to be significantly more heterogeneous than Potts would have it, and, accordingly, his account of them is of necessity (i.e. insofar as it does capture their behavior) less unified than he claims. Most important, Potts focuses solely on one facet of the meanings of these CIs: their interaction with at-issue content in the course of compositional semantic interpretation. But we argue that modeling the properties of CIs through a syntactically-driven compositional semantics falls short of providing an explanatory account of the nature of CIs. There are other important aspects of their meanings which are properly pragmatic, and which this account fails to capture. Understanding the difference between at-issue and CI content requires taking into consideration the way in which they contribute to the Information Structure of the discourse. Such an approach must take into account the interaction of compositionally derived meaning with contextual information, and hence crucially involves the interaction of semantics with pragmatics. We believe that if we take such interactions into account, the motivation for the proposed multidimensional approach is undercut. While the aim of this review is not to provide an alternative theory of CIs, we discuss possible directions in which Potts' contribution to the study of this notion could be improved.

In section 1 of this review, we will give a brief informal sketch of Potts' notion of CI and its relation to other types of contribution to meaning. This amounts to an overview of Potts' general introduction (Chapter 1) and preliminary arguments that CIs constitute a distinct class of meaning (Chapter 2), along with his summary review of their characteristics (Chapter 7). Potts divides the constructions that contribute CI content into two main types: supplements (appositives and parentheticals), analyzed mainly in Chapter 4, and expressives, analyzed in Chapter 5 . We will focus here almost exclusively on supplements; for Potts' more recent work on expressives and a number of responses to that work, see Potts (to appear) in a special issue of Theoretical Linguistics on Expressive Conventional Implicatures. In section 2, we outline and explore in some detail the formal apparatus Potts develops (in his Chapter 3 and an Appendix) and consider some of the predictions it generates. In section 3 , we consider the pragmatics of CIs, focusing on issues which Potts does not consider in his account: performativity, relevance, point of view, and presupposition projection. And in section 4, we consider the question of what it would mean for an account of CIs to be explanatory.

\section{Characterizing the class of Conventional Implicatures}

For Potts, CIs are meaning triggers that: ${ }^{2}$

- contribute to the meaning of the utterance in a conventional way, and hence are noncancellable, but

\footnotetext{
${ }^{2}$ Like Potts, we will use $C I$ to refer to both a kind of meaning and the expression that triggers that kind of meaning, so long as it is clear from context which sense it has.
} 
- are not part of the central, or at-issue content of the utterance, though they may take parts of at-issue content as argument(s); in fact they are "logically and compositionally independent of what is 'said (in the favored sense)"”, i.e. independent of the at-issue entailments; thus, they

- never take narrow scope with respect to operators in the at-issue content (a property he terms scopelessness), and hence are invariant under plugs to presupposition; and

- are generally speaker-oriented, except in direct quotations.

Potts argues that the meaning triggers that satisfy these criteria (his CIs), also satisfy the criteria for CIs originally suggested by Grice (1967), and in fact do so far better than Grice's own exemplars, but and therefore (hence agreeing with Bach (1999) that but is not a CI trigger). He models the behavior of the more diverse group of CIs given below with a sophisticated version of the kind of theory pioneered for conventional implicature by Karttunen and Peters (who were treating triggers that are generally regarded as presupposition triggers, not Potts' CIs), where the at-issue and conventionally-implicated semantic content are calculated in parallel.

Among supplemental expressions, Potts distinguishes two classes: (i) supplemental clauses and (ii) supplemental adverbs. An example of each type of construction is underlined in the examples below:

\section{A. Supplements}

\section{(i) Supplemental clauses:}

- As-parentheticals:

(2.13)(a) Ames was, as the press reported, a successful spy.

- Supplementary relatives:

(2.13)(b) Ames, who stole from the FBI, is now behind bars.

- Nominal appositives:

(4.59) Sheila believes that Chuck, a psychopath, is fit to watch the kids.

(ii) Supplemental adverbs:

- Topic-oriented adverbs (not “subject-oriented”, see discussion in section 3.3):

(2.15) 'Physically, the keyboard is smaller than I expected, and extremely well built —-there's no creaking or flexing. The keys look as if they will last well-including their paint. Thoughtfully, there is a clip-on cover for the connector while not in use.'

- Speaker-oriented adverbs:

(4.130)(b) Motorola said that, amazingly, it has no spare modems. 
- Utterance-level modifiers:

(2.16)(c) Frankly (speaking), Ed fled.

The final category, expressives (B) is taken by Potts to be the most prototypical of the CIs, displaying all of the properties he discusses (invariance under presupposition plugs, speakerorientation, and noncancellability).

\section{B. Expressives:}

(iii) Expressive attributive adjectives:

(5.39a) Sue’s dog is really fucking mean.

(iv) Epithets:

(2.22) Every Democrat advocating [a proposal for reform $]_{1}$ says [the stupid thing $]_{1}$ is worthwhile.

(v) Honorifics (based on the Japanese honorific system):

(2.25) Ame ga furi-mashi-ta. rain SUBJ fall-HON-PAST

'It rained.' (performative honorific)

(vi) German Konjunktiv I, implicating lack of speaker commitment to an embedded clause:

(2.26) a. Sheila behauptet, dass sie krank sei.

Sheila maintains that she sick be.KONJ

'Sheila maintains that she is sick.'

In more recent work on expressives by Potts (to appear) and others (cf. Potts \& Kawahara (2004)), significant revisions have been proposed to the theory of expressives in the book.

The syntactic and semantic behavior of the constructions presented above provide the empirical support for the logic whose discussion occupies the bulk of the book (see especially the third chapter). Potts claims that a unified account of the behavior of supplements and expressives is possible if we assume that they both contribute CI-content, and he spells out this contribution using a type-driven multidimensional translation language. An important claim, repeated several times in the book, is

...the question is not whether a multidimensional theory is motivated - it seems inevitable - but rather how best to formalize the notion. (p. 22)

Potts assumes that such an approach to meaning is already motivated by previous work that analyzes the denotation of a sentence in terms of tuples of meanings; he cites, among others, Karttunen and Peters' (1979) model for presupposition projection and Rooth’s $(1985,1992)$ alternative semantics for focus. 
In addition to the dimensional division between CI- and at-issue content, Potts also proposes a rich ontology of classes of meanings, schematically represented in a graph at the outset of the book (Figure 2.1, p. 23).

[Potts’ figure 2.1 here: see figures at end of submission]

The main division of content is determined by the notion of deniability. Commitments that are conventionally determined by the grammar may not be denied (entailments), whereas contextdependent implications, as they are associated with certain contexts of use but not with others, may be denied without contradiction. The class of meanings that are context-dependent further divides into conversational implicatures (not conventional, not speaker-oriented, not backgrounded) and conversationally-triggered presuppositions (not speaker-oriented, but backgrounded). According to Potts, even conversationally triggered presuppositions may have lexical triggers; he gives the example of the factive presupposition of before, which does not survive in certain contexts, as discussed by Levinson (1995) and Kadmon (2001).

Potts' main interest is in the class of entailments. Here, he draws a three-way distinction between at-issue entailments (not invariably speaker-oriented; vary under presupposition holes and plugs), conventional presuppositions (not speaker-oriented, backgrounded) and CIs. Crucially, he points out that the word "implicature" in the term CI (coined by Grice) may be misleading. He argues that this kind of meaning, as made apparent by the main branching in the graph, is not context sensitive and its behavior is not amenable to a pragmatic account; CIs are "narrowly grammatical entailments" (p.38). We will return later to the issue of how exactly to define at-issue, but Potts notes that it partially overlaps with other terms proposed in the literature such as "what is said" (in Grice’s sense), “assertion” (in Stalnaker's sense) or the "extensional” component of utterance meaning in Karttunen and Peters (1979). He does think that CIs are also assertions, saying that they are assertions with "a secondary role” (p. 24). He also notes that "intonational meanings," though not a part of the taxonomy, "function as triggers of non-at-issue meaning, but impose no further restrictions on what kind of meaning this is.” (p. 26)

Hence, not only does Potts propose a unified account of a range of prima facie unrelated phenomena, but in doing so he re-visits important questions about the general nature of semantic interpretation, questions raised earlier by the work of Karttunen \& Peters (1979), Horn (e.g. 1989, 1991, 2002), Rooth (1985, 1992), Kay (1990) and Abbott (2000), among others: Are there different kinds of meaning, and if so, how do they relate to each other? We'll return to this question and its ramifications for semantic theory at the end of this review.

\section{The Formal System}

Formally, Potts' theory involves two typed logics, connected via the interpretation function. The 'lower' logic $\left(L_{C I}\right)$ is the principal logic employed in the translation from English syntactic structures to an intermediate language of semantic parsetrees, the latter a sort of logical form where the semantic interaction between at-issue content and CI-functors takes place and is regulated through parsetree admissibility conditions. The 'upper' logic $\left(L_{U}\right)$ is similar to the logic typically used in Montague semantics, with the exception that this logic has additional atomic types for two kinds of "sentences”, questions and assertions. These are ordered pairs each consisting of a syntactic structure and its $L_{C I}$ parsetree translation. Potts is not entirely clear about the function of $L_{U}$. He uses it for modeling the behavior of utterance-modifying adverbials (to be 
discussed in section 3.3 below) and for shifting speaker orientation. Adverbials like honestly shift from speaker-orientation in assertions to addressee-orientation in questions; and speakerorientation is also shifted in direct quotation: Direct quotations may have CI content, but in them that content is attributed not to the actual speaker, but to the reported speaker, as we will see shortly. Although $L_{U}$ can, in principle, directly interpret at-issue content, and does in the case of the matrix of a direct quotation, Potts only uses $L_{U}$ when it has this orientation-shifting or utterance-modifying function. Moreover, all lexical entries except those of utterance modifiers like honestly are given directly in $L_{C I}$ types. So let us first focus on $L_{C I}$.

In order to distinguish the two types of asserted content, Potts separates the types for expressions of $L_{C I}$ into $e^{a}$, $t^{a}$, and $s^{a}$ for at-issue content and $e^{c}, t^{c}$, and $s^{c}$ for CIs. He then defines the set of types so that if $\sigma$ and $\tau$ are at-issue types, $\langle\sigma, \tau>$ is an at-issue type, and if $\sigma$ is an at-issue type and $\tau$ is a CI-type, $\left\langle\sigma, \tau>\right.$ is a CI type (3.18c,d, p.55). Note that types such as $\left\langle e^{c}, t^{c}>\right.$ or $\left\langle e^{c}, t^{a}>\right.$ are not well-formed in Potts' system. This reflects one of his central claims: that CIs are comments on at-issue content (and not, for example, comments on another $\mathrm{CI}$ ). But the converse does not hold, since we do not find at-issue content that is a comment on a CI. Thus, despite allowing $e^{c}$ and $s^{c}$ types (to maintain the formal parallel of the two type systems), $t^{c}$ is the only atomic CI type used in the book.

Potts uses $L_{C I}$ to develop a "semantic meaning language" consisting of the representations he calls Semantic Parsetrees, and he argues that model theoretic interpretation is crucially indirect, mediated by translation into parsetrees. A parsetree is a connected, rooted, acyclic graph where each node has maximally two daughters and only one mother, and nodes are associated with formulae of $L_{C I}$. Here is an example:

(1) $\mathrm{L}_{\mathrm{CI}}$ parsetree for Lance, a cyclist, is from Texas (see figures at end of submission)

It should be noted that parsetrees are derivation trees, as in Montague Grammar, not phrase structure trees. The real innovation is that at each node there may be more than one expression of the language of $\mathrm{L}_{\mathrm{CI}}$, as we see in the left-hand daughter of the root node in (1), with $\bullet$ being used as a metalogical device to separate different formulae at the same node. According to the tree admissibility rules, at a given node, according to the rules for tree admissibility, there will be at most one at-issue expression and at-most one CI expression (as distinguished by their types), so that at nodes with multiple formulae, these will always be of distinct types. Tree admissibility conditions over mother-daughter relations constrain these trees, specifying what combinations of daughter node expressions are licit and what the resulting mother expression will be. Below are two central tree admissibility conditions, Potts' (3.34) and (3.38):

\section{(3.34) at-issue application}

(see figures at end of submission)

(3.38) CI application

In (3.34) (p.62), we see the result of function-argument application for at-issue content, the functor in the left daughter applying to its argument the right daughter to yield the content of the mother. The CI-type expressions in dotted lines below - are optional, leaving open the possibility that the daughters are also associated with CIs; but if they are, material below $\bullet$ plays no role in at-issue application

(3.38) is the tree-admissibility condition for CI application. Again the optional terms below play no role in the application. The left-daughter $\alpha$ is a functor of CI-type $\left.\left(<\sigma^{\mathrm{a}}, \tau^{\mathrm{c}}\right\rangle\right)$, while the 
right daughter $\beta$ is an argument of the appropriate at-issue type $\sigma^{\mathrm{a}}$. On the root node, below $\bullet$ we see the result of the application of $\alpha$ to $\beta$, which is of the type we would expect under functionargument application, $\tau^{c}$. Above $\bullet$, we see that the at-issue content of the daughters, i.e. $\beta$, has become the at-issue content of the mother. The left-hand daughter thus makes no contribution to the at-issue content of the whole constituent.

Potts claims that no functor contributes to both CI and at-issue content, so that any given functor combines with its argument via either (3.34) or (3.38).

Potts’ (3.39), a sub-structure of (1) above, exemplifies CI application:

$$
\mathrm{L}_{\mathrm{CI}} \text { parsetree for Lance, a cyclist... (see figures at end of submission) }
$$

A parsetree is interpreted as an entire structured object via the rule of parsetree interpretation in (3.46):

$$
\text { Parsetree Interpretation (see figures at end of submission) }
$$

This tells us that the interpretation of a parsetree in $\mathrm{L}_{\mathrm{CI}}$ is the ordered pair consisting of the interpretation of the at-issue term on the root node (the expression above $\bullet$ ) and the set of interpretations of all the propositional-type CI terms on any nodes in the tree. The multidimensionality in Potts' fragment is captured here: the at-issue content of the entire parsetree is the first element in this ordered pair, while the CI content is the second element, a possibly nonsingleton set of propositions. As is fairly standard, the interpretation is relative to some "interpreted structure $M_{i}$ " (an intensional model, as he makes clear later) and a variable assignment.

At this point, we notice two important things: 1 . Potts' system is not resource-sensitive (meaning that it is not the case that each lexical item is used once and only once in the compositional interpretation of the sentence), since in parsetrees like those in (3.38) the at-issue content ( $\beta$ ) plays a role in multiple dimensions. 2. Earlier literature on presuppositions had proposed various mechanisms to account for their "projection" to the root note, e.g. some sort of storage mechanism ${ }^{3}$ or heritage function (Karttunen \& Peters 1979). With the addition of parsetrees, Potts is able to dispense with such mechanisms for interpreting the CI content at the root node, because each dimension corresponds to one entry in a meaning-tuple, the result of Parsetree Interpretation.

Because there is no heritage function and the parsetree structure plays a role in interpretation, this "meaning language" plays an essential role in characterizing what it is to be a CI, and the way that CIs contribute to interpretation. Potts argues that this cannot be captured either in the syntaxsince CIs are syntactically heterogeneous-or in the model theoretic interpretation itself, where it is not possible to distinguish the truth conditional contributions made by utterances like his (3.9a), with CIs, and (3.9b), without:

(3.9) a. Chuck, who killed a coworker, is in prison.

b. Chuck killed a coworker, and Chuck is in prison.

\footnotetext{
${ }^{3}$ Yusuke Kubota (p.c.) points out that Pollard \& Sag (1994) gave a treatment of Korean honorifics which used a storage function to encode their honorific content as a constraint on context.
} 
Of course, this comes at the cost of positing parsetrees as objects in the ontology of the grammar. But Potts argues that this is not really so very different from standard practice in contemporary semantics, where, "Although one hears continued talk of direct interpretation as a desirable framework, the talk does not match the practice of linguists. Arguably, every present-day framework that has been applied to a sufficiently wide range of data of both a syntactic and a semantic nature has ended up with crucial appeals to a meaning language in one form or another" (p.70), citing DRT (Kamp \& Reyle 1993), Glue semantics (Asudeh \& Crouch 2002), and LFbased semantic extensions of the Minimalist Program. ${ }^{4}$ However, a growing body of research on direct compositionality (cf. Barker \& Jacobson (2007)) argues against the need for a meaning language. Potts does briefly discuss the directly compositional approach (pp. 71-73), saying that its syntactic categories are "semantically-informed," which could serve the same function as his type-theoretic distinction. He says that if his theory were recast in that way, it could be considered directly compositional. Hence, he has not made the case that his system would be the best possible implementation of multidimensionality.

With respect to the interpretation function for Parsetree interpretation, (3.46), Potts defines a function [symbol for barred- $h$ here] which maps discourse participants (a subset of the domain of individuals) to intensional models, their "world views". This is part of what he calls a 'discourse structure' (3.59, p.76), which also includes a common set of domains for the models, so that "everyone is talking about the same stuff" (76), and a valuation function $V_{D}$ that takes "constants of $L_{U}$ to functions formed from objects in $D_{e} \cup D_{u} \cup\{0,1\}$, constrained so that if $\alpha$ is of type $\sigma$, then $V_{D}(\alpha) \in D_{\sigma}$ " (76). The interpretation function for a discourse structure $D$, speaker $s$, and addressee $a$ is given in (3.60) (p.76):

(3.60) a. $[|\varphi|]^{\mathrm{D}, \mathrm{s}, \mathrm{a}}=\mathrm{V}_{\mathrm{D}}(\varphi)$ if $\varphi$ is a formula of $L_{U}$.

b. $[|S|]^{\mathrm{D}, \mathrm{s}, \mathrm{a}}=$ the value of $S$ determined by (3.46) if $S$ is a parsetree for $L_{C I}$.

This interpretation function tells us that we need different mechanisms for the two different logics. For $L_{U}$, we are referred to the valuation function defined in the previous paragraph, which is presumably specified over the domains in the discourse structure, mapping to entities in a model characterizing the world view of the speaker or (for some questions) addressee or some other individual to which orientation has been shifted. How this happens is not specified. For $L_{C I}$ expressions, (3.60) refers us to the interpretation “determined by (3.46)", which includes its own interpretation function. The $L_{C I}$ interpretation function is only given in the appendix in (A.2.5) (reproduced below). While Potts has given the semantics of some lexical items in the book, nowhere has he given an example of the interpretation of a full sentence with a CI. Instead, he consistently gives the meaning language representations of his examples, so that a reader walks away understanding the semantic combinatorics of CIs rather than their interpretations.

(A.2.5) Interpretation for $L_{C I} \quad$ (see figures at end of submission)

\footnotetext{
${ }^{4}$ Potts' comments in connection with the last are particularly interesting (p.71):

Not since the late 1980s have these researchers taken seriously the idea that all covert movement operations must obey all known syntactic constraints. The consensus is that constraints on covert movement are different from those on overt movement; examples of this position include Sauerland and Heck 2002 and Percus and Sauerland 2002. But this is just to say that the operations held to deliver the interpreted structure are not syntactic but semantic. LFs are in fact a meaning language.

A reviewer points out that “the fact that a level like LF is not subject to surface constraints doesn't mean that it's not a syntactic level.” This issue is surely more controversial than Potts leads us to believe.
} 
Once again in (A.2.5) we find that expressions are interpreted with respect to intensional models. Informally, Potts makes it clear that main clauses are ordinarily interpreted relative to the actual speaker's model:

If I say, 'Ed fled', I stand in the utterance relation to the sentence Ed fled. When we interpret the content of this sentence, we do so in the intensional model $M_{\text {chris }}$. This provides a precise characterization of the speaker orientation of main clause assertions. By the rule of parsetree interpretation, (3.46), all CI propositions are also interpreted in $M_{\text {chris }}$, thereby achieving speaker orientation for them as well. (p.77)

We are now prepared to tackle a simplified example (2) with an expressive CI (that jerk) whose analysis following Potts is given in (3). ${ }^{5}$ However, as with the translation from English to $L_{C I}$, the reader is left to guess how this would work.

(2) Jed said "that jerk Ed fled".

(3) Derivation of (2), as spoken by Chris (see figures at end of submission)

Potts says that the speaker parameter correctly shifts from Chris to Jed in the $L_{C I}$ clause due to the presence of quotation marks. ${ }^{6}$ Once the speaker parameter correctly shifts for the at-issue portion of the parsetree, all of the CI content is also shifted in accord with the parsetree interpretation rule, matching empirical observations. This yields speaker-orientation for the CIs, but as Potts notes elsewhere in the book, main clause assertions tend to be speaker-oriented as well, "simply because they do not supply any other agent to whom the content might be attributed” (p.213). How the speaker parameter is assigned for each type of content remains a mystery and appears to be "very complicated” and "subject to a rather extreme degree of contextual variability” (Potts, p.c.).

Now we turn to the interpretation of supplements. As we saw, the lexical triggers of expressive CIs have the CI types built into their lexical meaning. But what triggers CI types in the case of phrases that sometimes appear as supplemental CIs but can also appear as at-issue content? Consider the following example:

(4) a. The author, who is a linguist, ran a marathon

b. The author who is a linguist ran a marathon

The phrase who is a linguist contributes a CI in (4a) but not (4b). Potts notices that in examples like these, or (2.49) (p.37), commas in the written form and "comma intonation" in the spoken form differentiate the two; comma intonation seems to involve prosodically setting the relevant expression apart from the rest of the utterance via a pause or pauses. He thus defines the CommA operator in (4.114), on the understanding that COMMA is the semantic reflex of the intonational trigger.

(4.114) COMMA $\left.>\lambda \mathrm{X} \lambda \mathrm{x} \cdot \mathrm{X}(\mathrm{x}):<<\sigma^{\mathrm{a}}, \mathrm{t}^{\mathrm{a}}\right\rangle,<\sigma^{\mathrm{a}}, \mathrm{t}^{\mathrm{c}}>>$, where $\sigma \in\{\mathrm{e}, \mathrm{s}, \mathrm{t}\}$ (p.136).

\footnotetext{
${ }^{5}$ We will follow Potts' practice of extensionalizing examples where intensionality isn't crucial.

${ }^{6}$ It is not clear to us how the grammar sees quotation marks; if it is based on an intonational cue, Potts doesn't mention how that plays into interpretation (though this is understandably a complex issue). It is also not clear that a consistent intonational cue is even present.
} 
Though CommA could combine with its argument via the rule for CI application from (3.38), this would lead to the at-issue argument, linguist in (4a), being available in more than one dimension, which would create a type-mismatch: The lexical content of supplements like the supplementary relative in (3a) serves solely to derive the CI, and CI-application as described in (3.38) would incorrectly predict that they would also contribute to at-issue content. To avoid this, Potts treats COMMA as a 'feature term' and defines a second tree admissibility condition, given in (3.42) (p. 66) for features, which also include Chierchia’s (1988) kind and de-kind operators and Partee’s (1987) lift operation.

(3.42) Feature semantics (p. 66)

(see figures at end of submission)

The mother node in parsetrees exemplifying this schema has only one expression, of CI type, so that none of the content of the supplemental CI is passed along to at-issue content. Though we do not typically think of type-shifters as having the formal status of features, let us suppose that feature is just shorthand for 'combination of an argument with a non-lexical functor.' But still this doesn't explain the difference in licensing between operators like kind, lift, etc. that are used as needed in a type-driven approach, and COMMA, which is licensed by a phonetic environment. Moreover, it is not clear how the applicability of COMMA is to be determined from a compositional point of view: The trigger cannot be intonation alone, for there are, of course, instances of comma intonation that do not result in CI interpretations. ${ }^{7}$. For example, a variety of sentential adverbials, including if-clauses and temporal adverbials, may occur internal to the root clause they modify, set apart by pauses on either end: Ed, if/before he fled, was very secretive. Yet Potts presumably would not want to treat these adverbials as CIs via the semantically-contentful CoMMA feature. Thus, it seems that Potts would be forced to enrich the feature semantics tree admissibility condition to guarantee that in case the feature in question is COMMA, the daughter node must be one of the appropriate set of constructions which can serve as supplements.

Other work by Bonami, Godard \& Kampers-Mahne (2004) shows that intonation and semantic status of adverbs are often not correlated. They call the property of adverbs constituting their own prosodic phrases incidentality and the property of their being a semantic comment on an assertion parentheticality. In both of their examples (5) and (6), below, the French evaluative adverb malheuresement is interpreted as parenthetical, although it is incidental only in (5); both sentences mean 'my brother unfortunately missed his plane'.

(5) Mon frère, malheureusement, a raté son avion.

(6) Mon frère a malheureusement raté son avion.

Another problem for CommA is an empirical one. As defined in (4.114) above, $\sigma$ ranges only over the atomic categories, meaning that CoMmA can take, for example, $<\mathrm{s}^{\mathrm{a}}, \mathrm{t}^{\mathrm{a}}>$ or $\left\langle\mathrm{e}^{\mathrm{a}}, \mathrm{t}^{\mathrm{a}}>\right.$ arguments, but not $<<\mathrm{s}^{\mathrm{a}}, \mathrm{t}^{\mathrm{a}}>, \mathrm{t}^{\mathrm{a}}>$ or $<<\mathrm{e}^{\mathrm{a}}, \mathrm{t}^{\mathrm{a}}>,<\mathrm{e}^{\mathrm{a}}, \mathrm{t}^{\mathrm{a}}>>$ arguments. This is important for modeling the contrast we see in (4.109) (p.135):

(4.109) a. Alonzo built the canoe, as the foreman said he would (though not in the manner they expected him to build it).

b. Alonzo built the canoe as the foreman said he would (with an ax and elbow grease).

\footnotetext{
${ }^{7}$ This was independently noticed by Bonami and Godard (2005), cf. footnote on their p.4.
} 
The parenthetical in (4.109a) should be treated as a CI, while the manner adverbial in (4.109b) should not. The argument specification for COMMA and the following lexical entry for 'mannerAs' work together to prevent a CI interpretation for (4.109b):

(4.112) as $\mathrm{s}_{\text {manner }} \ldots<\mathrm{t}^{\mathrm{a}},<<\mathrm{e}^{\mathrm{a}}, \mathrm{t}^{\mathrm{a}}>,<\mathrm{e}^{\mathrm{a}}, \mathrm{t}^{\mathrm{a}}>>>(\mathrm{p} .136)$

Once as takes its sentential complement, the result is of type $<<\mathrm{e}^{\mathrm{a}}, \mathrm{t}^{\mathrm{a}}>,<\mathrm{e}^{\mathrm{a}}, \mathrm{t}^{\mathrm{a}}>>$. COMMA cannot apply, since this argument is not a simple set of individuals, worlds, or truth values. While this yields the result that Potts wants for this data, it is problematic for other data, such as topicoriented adverbs like thoughtfully in (4.136) (p.144):

(4.136) a. Thoughtfully, the batteries were included.

b. $L_{\text {CI }}$ parsetree for (4.136a), p.144 (see figures at end of submission)

The denotation for thoughtfully in this diagram shows that it takes as arguments a proposition and a discourse topic, the denotation of $x_{1}$. This is not a valid parsetree in Potts' logic, however: thoughtfully cannot be an argument of COMMA for the same reason that as the foreman said he would cannot be an argument of COMMA above. We do not see any reasonable way of revising Comma to admit the CI in (4.136a) but not the would-be CI in (4.109b).

Yusuke Kubota (p.c.) points out that Potts could avoid this problem if he treated thoughtfully as lexically specified to be a CI-trigger. However, Potts points out repeatedly that supplemental CIs are triggered by expressions that have at-issue usage as well (e.g. thoughtfully as at-issue in He approached the problem thoughtfully), and he generally attempts to derive the CI usage via the compositional rules. If he treated thoughtfully as ambiguous between at-issue and CI types, this would leave unexplained why this particular adverbial resists the type of treatment generally available, shifting in the course of compositional interpretation from at-issue to CI type. We return to this question from a different angle in section 3 below.

Besides CI application and the feature-semantic rule used for the interpretation of CIs with COMMA, Potts proposes a third tree-admissibility condition for CI derivation:

\section{(3.41) Isolated CIs (p.66) (see figures at end of submission)}

He points out (p.66), “The most noteworthy feature of this rule is that it works only for adjoined CI content that is saturated.” This is because (3.46), parsetree interpretation, only applies to CI expressions that are of type $t^{c}$. The examples to which Potts applies (3.41) are all cases in which he claims that the $\mathrm{CI}$ bears no semantic function-argument relation to the non-CI material to which it is adjoined, so that CI application in (3.38) cannot apply (p.125). A selection of examples requiring the Isolated CI rule for interpretation are listed below (pp.65-66,125,128,169-171):

(3.40b) That's fantastic fucking news! (expression of emotion)

(4.76) The students, most of them linguists, missed the bus (small clause construction)

(4.79a) Luke has - and you'll never believe this - eaten fifty eggs (niched conjunction)

(4.79b) Jeb, that guy Dick's always talking about, will someday rule the earth (interjection)

(4.80) Every climber, adventurers all, ... (quantificational anchor)

(5.39a) Sue's dog is really fucking mean (expressive attributive adjective) 
For example, in (3.40b), according to Potts we cannot apply CI application to yield an expressive CI triggered by fucking because there's no fuckee argument. Rather, "the CI proposition [suggested by fucking in such examples is] that the speaker is in a heightened emotional state" (p.170). Presumably, Potts is assuming that fucking in this expressive usage has a distinct lexical entry from its use as a participial form of the verb. Similarly, Potts claims that in (5.39a), really modifies not fucking or fucking mean, but mean, with fucking contributing an isolated CI, as in (3.40b). ${ }^{8}$ Potts takes (4.79a) to assert that Luke has eaten fifty eggs while conventionally implicating that the addressee will never believe what the speaker is asserting. Here, this in the supplementary expression and you'll never believe this presumably refers to the denotation of Luke has eaten fifty eggs, the at-issue content contributed by the main clause. But otherwise there is no relation between the supplement and the at-issue content, since the supplement is not of a type to take the main clause as an argument. Thus, the CI contributed by the supplement is derived via the Isolated CI rule. The subject of (4.80) every climber, is quantificational, not referential, and CIs cannot be bound under quantification in the at-issue content, as we would expect given the semantic independence of CIs under Potts' rules. Hence in (4.80) the appositive adverturers all cannot directly modify the subject under CI application, so Potts takes the appositive to be an independent CI, with all presumably referring to the pragmatically salient group of climbers in the domain of every. Hence, it seems that the Isolated CI rule is a catch-all for phenomena which cannot be correctly accounted for using CI application or COMMA.

But trying to capture all these kinds of cases with one rule is rather awkward. For example, it seems arbitrary to claim that the appositives in (4.76) and (4.80) are of type $t$. Moreover, for some of these examples, slight changes result in a bona fide CI, and it seems that these should then be modeled similarly. Compare, for example, (4.79a) with (7), with a speaker-oriented adverb, or (4.79b) with (8), with a nominal appositive.

(7) Unbelievably/Amazingly, Luke has eaten fifty eggs.

(8) Jeb, a linguist, will someday rule the earth.

(4.79b) and (8) are so closely parallel both structurally and in terms of their semantic type that it seems unexplanatory to treat (4.79b) as an 'interjection', and thus not a regular CI, while (8) is a completely typical case of a CI that works within Potts' system, where its analysis is parallel to that of (3.39) above, using the CI application rule. By the same token, both the 'niched conjunction' in (4.79a) and the speaker-oriented adverb in (7) provide CI content that amounts to incredulity of the speaker toward the propositional content of the main clause assertion Luke has eaten fifty eggs. However, in Potts' theory, the CI contribution of (7) is treated as typical while the contribution of (4.79a) requires the "Isolated CI" rule, thus failing to capture the intuitively perceived parallelism of their meanings.

Now that we have seen examples of expressives and supplements and isolated cases of each, we might ask to what extent supplements and expressives are actually related within this logic. Potts argues that one of the goals and benefits of his formal system is that it unifies the treatment of these two categories, citing past work on epithets in Lebanese Arabic to suggest that they should

\footnotetext{
${ }^{8}$ Once one exception is allowed via this method, we cannot see anything that would prevent its application to other cases, including an example of Potts' where we contest his judgment: he claims that Juan is too fucking Swedish to know about jet skis is ungrammatical (p.169), but that and similar examples such as Randy is too fucking American to appreciate good foie gras seem perfectly acceptable to us. As Judith Tonhauser (p.c.) suggested to us, it is very easy to find lots of real examples of this via Google. The reader is invited to try!
} 
receive a parallel analysis. But the mechanisms that yield the two types of CI in Potts' theory are quite independent of one another. The central class of supplements require the CoMmA feature for interpretation, whereas expressives not only don't require it, they have no use for it. It is true that these phenomena are computed within the same logic. But one could have the same formal system minus one or the other of the relevant mechanisms, accounting for only one of the two classes of data. Even though two phenomena are accounted for within the same formal system, if the mechanisms which are used for them are completely independent of one another and are nonoverlapping in their application, then there is no unified account of the phenomena.

\section{The Pragmatics of Conventional Implicatures}

Potts opens Chapter one as follows:

I hope readers of this book are struck by how little pragmatics it contains.

He does not disappoint. As their name suggests, conventional implicatures are conventionally triggered. As is appropriate to a conventionally triggered aspect of the meaning conveyed by an utterance, Potts' CIs are calculated as part of the compositional interpretation of the utterances in which they arise, via the regular meanings of the lexical items and other conventional features (like comma intonation) of those utterances. From this, Potts concludes:

The distinction between at-issue and CI content is often entirely about semantic composition. It is properly... a syntactic fact about the logic of the natural language semantics. (p.15)

But we contend that leaving matters at this begs some important questions. Consider a related phenomenon: Few today doubt that conventionally triggered presuppositions, since they are conventional, are generated as a function of the compositional interpretation of the utterances in which they occur. But it would be quite unsatisfactory to say this and no more. Most now view presuppositions - whether conventionally triggered or not-as constraints on context of some sort and hence as bearing on the relationship between an utterance and the context in which it is uttered. Without shedding light on the nature of that essentially pragmatic relationship, one has not adequately explained presupposition.

In this section we want to explore facets of the pragmatics of CIs. We will offer several arguments intended to show that a fully adequate theory of conventional implicatures will have to take into account essentially pragmatic phenomena that Potts ignores. The first of these, discussed in section 3.1, involves the analysis of utterance-modifying adverbial CIs like frankly. Then in section 3.2 we consider the distinction between at-issue content and CI content, and in 3.3 the question of the speaker-orientation of Potts' CIs. In section 3.4, we discuss the issue of the independence of CIs from at-issue content, arguing that in fact there is more interaction than Potts' proposal would predict. We present evidence that CIs do interact with other types of meaning in the course of context update, an essentially pragmatic process ignored in the static semantics for CIs offered by Potts. 


\subsection{Utterance Modifier CIs and the Performative Hypothesis $^{9}$}

The Performative Hypothesis was a theory that in the deep structure of every sentence is a performative matrix clause, something like I state (to you) that, which may be deleted at surface structure. ${ }^{10}$ A number of syntactic arguments were offered for this thesis and it was adduced in attempting to explain a wide range of phenomena (Ross 1970, Sadock 1974, Lakoff 1972, 1975), including, for example, the occurrence of first and second person reflexives without overt antecedents. One of the central arguments hinged on the use of performative adverbs, as in (9)(11):

(9) Frankly, Sheila dislikes you.

(10) What do you want for dinner, because I'm going to the grocery?

(11) In case you're hungry, there are leftovers in the refrigerator.

It seems clear that what such adverbials modify is not the assertion associated with the main clause of the utterance, but the speech act thereby performed (Austin 1962).

One of the main aims of the performative hypothesis was to reduce Austin's illocutionary force to an aspect of semantics. E.g., the above would mean:

$\left(9^{\prime}\right) \quad$ I tell you frankly that Sheila dislikes you.

$\left(10^{\prime}\right)$ I ask you because I'm going to the grocery what you want for dinner.

$\left(11^{\prime}\right)$ I tell you in case you're hungry that there are leftovers in the refrigerator.

But careful consideration shows a problem with this approach — the so-called performadox of Boër \& Lycan (1980): The truth conditions for (9)-(11) are not the same as those for $\left(9^{\prime}\right)-\left(11^{\prime}\right)$. For example, $\left(9^{\prime}\right)$ is true just in case the speaker tells the addressee the proposition in (9) and does so in a frank manner; whereas the truth of (9) itself requires that it be true that Sheila dislikes the addressee. $\left(10^{\prime}\right)$ is true just in case the speaker does ask the question in (10) and her reason for doing so is that she's going to the grocery. But (10) itself denotes an interrogative, typically interpreted as a set of propositions, roughly all of those that would constitute answers to that question; so (10) is neither true nor false. Since tell neither presupposes nor entails the truth of its complement sentence, uttering $\left(9^{\prime}\right) /\left(11^{\prime}\right)$ does not entail $(9) /(11) .\left(9^{\prime}\right)$ may be true even though Sheila does not dislike the addressee.

As we have seen, Potts treats some of these adverbials as supplemental CIs, including frankly, confidentially, and the in case $S$ type, taking them to be "utterance-level modifiers", functors which take propositional at-issue content to yield CIs. He does not discuss performatives or the relevant literature. However, his theory constitutes a significant improvement over the performative hypothesis for those adverbs that he treats. The CIs associated with frankly, though they are on a different dimension than the at-issue content of the utterance, are still semantic, and hence are entailed as they were in the performative hypothesis. But they are generated independently of the at-issue truth conditions for the main clause in examples like (9)-(11), avoiding the performadox. Similarly, if John utters (12), this entails the truth of (13), as well as

\footnotetext{
${ }^{9}$ We are grateful to David Dowty (p.c.), who pointed out the relevance of the Performative Hypothesis for Potts' treatment of supplements, and for very stimulating discussion of the relevant issues.

${ }^{10}$ For a useful overview of the Performative Hypothesis and the associated literature, see Levinson (1983), Chapter 5.
} 
the truth of Ed wears a toupee, the two propositions arising from different dimensions of the meaning of (12):

[John:] Confidentially, Ed wears a toupee.

John said confidentially that Ed wears a toupee.

Moreover, Potts notes that although utterance modifiers cannot be embedded within at-issue content, Thorne (1972) had observed that they can modify other supplements, like supplementary relatives, so that they are not restricted to modifying root clauses (p.146):

(4.141b) We interviewed Lance, quite frankly the best cyclist in the world right now, about his plans for the future.

To capture this behavior, as well as the fact (observed by Bellert 1977) that utterance modifiers can modify speaking, as in frankly speaking, Potts treats these functors differently from other CI triggers, using the upper layer of his logic, $L_{U}$, to capture their contribution to meaning. This permits him to define relations between discourse participants and utterances. Within $L_{U}$, he defines the relation utter between speakers and sentences, the latter taken as pairs of a syntactic structure and its associated semantic parsetree in $L_{C I}$. An utterance is the result of applying utter to its arguments. Then frankly or confidentially modifies an utterance in $L_{U}$. Utterance modifiers like these thus behave as manner adverbials at the discourse level, parallel to their occurrence within $\mathrm{L}_{\mathrm{CI}}$ as simple manner adverbials, as needed for examples like (13). In the supplemental use in examples like (12), "the adverb frankly is not part of the $\left[L_{C I}\right]$ sentence it modifies in either the syntactic or the semantic sense” (p.149), accounting both for its semantics and for its nonembeddability in this use.

This seems to be the general function Potts has in mind for utterance modifiers (§4.7.3, 145-50): They serve in $L_{U}$ to modify utterances. Since utterance modifiers can modify CIs, the semantics must guarantee that "speakers are seen as having uttered their supplements," though Potts does not guarantee this in his fragment, and only hints (p.150) that one would use meaning postulates to do so. Though neither Potts' discussion nor the fragment is clear on this point, this might suggest that the relationship between $L_{C I}$ and $L_{U}$ generally involves interpreting both at-issue and CI content as utterances at the discourse level. If that were the case, he would actually be reconstructing the performative hypothesis, albeit in a distinct, non-at-issue dimension of meaning.

But what is this dimension? Unlike other kinds of supplements that are part of the sentence they modify within $L_{C I}$, because utterance modifiers like frankly do not occur in $L_{C I}$ parsetrees they don't truly belong to either of the dimensions defined by the at-issue and CI types of that logic. And if we have CIs like these that meet Potts' criteria but do not belong to either of the two types that constitute his two dimensions, the role of the logic in defining what it means to be a CI becomes muddled. We might say that $L_{U}$ simply introduces yet another dimension of meaning, that in which utterances, as opposed to propositions or other truth conditional entities, may be modified. But in what sense is this dimension merely a reflection of compositional semantics? What is modified is not the sentence or its compositionally derived parsetree in the meaninglanguage, but the utterance, and the latter is a fundamentally pragmatic entity, as everyone from Bar-Hillel (1971) on has agreed. From this, it seems reasonable to call into question the claim that Potts has given a unified account of supplemental CIs, including the utterance modifiers along with the types of adverbial supplements treated with COMMA. 
The problem of how these adverbials interact with the pragmatics of utterance has another reflex in Potts' work. He argues that when a speaker utters an example like (4.149a), s/he is thereby committed to the truth of the complement of say, explaining the infelicity of the second sentence of (4.150) on the grounds of contradiction:

(4.149a) I'd say that, just (speaking) between you and me, Ed fled with the winnings.

(4.150) I'd say that Ed fled with the winnings. \#But I did not (do not) say that Ed fled with the winnings.

He proposes to guarantee this contradiction with the meaning postulate in (4.151) (p.151): ${ }^{11} 12$

(4.151)For all $x$ and $\lceil S\rceil$, if $\left[[\lceil\text { utter }\rceil(\lceil x \text { says } S\rceil(x)]]^{\mathrm{D}, \mathrm{s}, \mathrm{a}}=1\right.$, then $[[\lceil\text { utter }\rceil(\lceil S\rceil)(x)]]^{\mathrm{D}, \mathrm{s}, \mathrm{a}}=1$

But this is problematic. First, the modal hedge would ('d) in each of these examples weakens the corresponding statement, and due to its presence, it isn't clear that the meaning postulate Potts proposes would technically apply. Because of the hedge, it isn't clear that (4.150) should be taken to be a semantic contradiction, nor that (4.149a) should be taken to entail that according to the speaker, Ed fled with the winnings. It surely at least conversationally implicates it, very strongly. Hence, we might say that the speaker of (4.149a) means ${ }_{n n}$ (in Grice's sense of non-natural meaning) that Ed fled with the winnings. But entailment is another matter.

Moreover, the proposed meaning postulate is reminiscent of Lakoff's (1975) response to the Performadox, claiming that an assertion is true iff both the performative clause and its complement clause are true, as in examples like (14):

I state to you that the earth is flat.

I.e., Potts' meaning postulate attempts to guarantee semantic transparency in one particular performative embedding matrix. But just like Lakoff's approach, it runs into problems because it is an attempt to reduce to semantics (entailment) a phenomenon that is arguably pragmatic. Let us grant for the moment that we take the speaker in (4.149a) to be committed to two propositions: that the speaker said that Ed fled and that Ed fled. But do we really want the utterance by $x$ of $x$ says that $S$ to entail the utterance of $S$ by $x$ ? Though the meaning postulate in (4.151) doesn't completely spell out the meaning of utter, Potts surely means more by his meaning postulate than just that the speaker spoke the words in the subordinate clause; otherwise it would not guarantee the contradiction he wants to derive for (4.150). But an utterance in the richer sense he seems to intend is a pragmatic phenomenon, a sort of speech act involving commitment to truth; it is not the same kind of thing as a proposition. We might want to argue, for example, that on the sense of utter relevant for (4.151), the speaker of (14) did not utter the earth is flat, any more than we would say that of the speaker of (15), as reflected in the felicity of the follow-up in (16):

(15) I deny that the earth is flat.

(16) I deny that the earth is flat. I do/did not say that the earth is flat.

\footnotetext{
${ }^{11}$ Potts' formula is missing a close-parenthesis after [x says $S$ ].

${ }^{12}$ Here, Potts uses corner brackets for $L_{U}$ terms to distinguish them from $L_{C I}$ terms. As an anonymous reviewer notes, the $x$ inside the corner-quotes makes no sense here. S/he suggests Potts might mean instead:

For all $x$ and $\lceil S\rceil$, if $[[\lceil\text { utter }\rceil(\lceil\operatorname{I} \text { say } S\rceil(x))]]^{\mathrm{D}, \mathrm{s,a}}=1$, then $[[\lceil\text { utter }\rceil(\lceil S\rceil(x))]]^{\mathrm{D,s,a}}=1$

That seems to be what's at issue. But our main point is unaffected by this technical detail.
} 
All these matters are closely related to the semantics of quotation, about which there is a growing body of interesting work. See especially Geurts (1998), Recanati (2001), Potts (2007), and especially Geurts \& Maier (2005) for a thread that bears directly on the present discussion.

Summarizing, it isn't clear that the class of adverbials that Potts calls utterance level modifiers are the same sort of thing as the other supplemental CIs, either in their observed behavior or in his technical implementation. Their treatment arguably requires a theory of the relationship between compositional semantic interpretation and the pragmatics of speech acts, which goes well beyond the purview of Potts' theory.

In the remainder of this section, we will focus on those CIs considered by Potts that are not triggered by the utterance modifiers discussed in this section. Whatever apparatus may be appropriate for treating the performatives, it is arguably not purely a facet of compositional semantics. The other supplemental CIs Potts considers have a stronger claim to constitute a distinct semantic dimension of the meaning of an utterance.

\section{2: $\underline{\text { CI-content vs. at-issue content }}$}

One important question that remains unaddressed by Potts is what distinguishes at-issue content from the other types of meaning in his taxonomy. The term is never defined in the book, and at different points at-issue is treated as being equivalent to "what is said" (in Grice's sense), or to the “regular content” (p. 210), “primary entailment” (p. 214) or "prominent entailment” (p. 214) of a sentence. Crucially, the reason why these semantic entailments are considered to be primary or prominent is not fleshed out. Contrary to what Potts says (pp.24-25), this is not merely an insubstantial terminological issue that is clarified by the logic he proposes. Rather, we believe it reflects an important unresolved issue.

Potts models the difference between at-issue and (non-utterance modifier) CI content as a difference in types:

"...CI content is model theoretically the same as at-issue content...Thus, we are led to the conclusion that the distinction exists only at the level of the meaning language. Within this realm, one can imagine a variety of different technical implementations. The one that provides the most satisfactory formal account within the confines of present semantic theories is this: at-issue and CI content are distinguished type-theoretically.” (p. 54) ${ }^{13}$

The division into $e^{a}, t^{a}, s^{a}$ and $e^{c}, t^{c}, s^{c}$ discussed earlier is intended to provide a formal implementation for the multidimensionality of meaning, i.e., to provide a model that allows for the computation of at-issue and CI content in a parallel way, crucially yielding independent propositions in the final interpretation. As discussed above, this is achieved through the parsetree interpretation rule in (3.46).

\footnotetext{
${ }^{13}$ It is possible to imagine other approaches to multidimensionality besides the type distinction Potts proposes. An anonymous referee brought Portner (2005) to our attention, wherein he proposes an alternative framework for multidimensionality, technically parallel to Rooth's focus semantics, with one interpretation function for ordinary content and another for expressive content.
} 
But how are we to know, for any given constituent, whether it should contribute to at-issue or to CI content? For example, in the slifting construction illustrated in (4.4a) below (Potts p.92, originally due to Ross 1973), Potts claims that the underlined expression is not a CI:

Max, it seems, is a Martian.

He claims that (4.4a) is equivalent to it seems that Max is a Martian; hence, it seems cannot be a CI-trigger, because it plays a role in the calculation of at-issue content: Unlike an utterance of Max is a Martian, the speaker is not unequivocally committed to Max's being a Martian. But what, then, are we to make of the following examples (not discussed by Potts)?:

(17) John is upset that Mary, apparently, has left town.

(18) Max is going to the concert because Sue seemingly has tickets.

In (17), it seems to be the speaker who is hedging on whether Mary has left town; it could be true even though John himself is quite convinced that she has left. For (18) to be true, only the speaker needs to suspect that Sue may not have tickets; Max may be unaware of that possibility. But if (17) and (18) do involve CIs, so that these adverbs should be treated in Potts' system in a parallel way to speaker-oriented adverbs like amazingly or luckily, this undercuts the argument that it seems in (4.4a) is not a CI, for it appears to make just the same contribution to the meaning of the whole as do the sentential adverbials to (17) and (18). Of course, one might try to argue that the sentential adverbials apparently and seemingly are ambiguous, precisely in serving either as atissue functors or as CI triggers, but such a stipulation strikes us as unsatisfactory in this case.

Overall, Potts has more to say about what CI and at-issue content have in common than about what differentiates them. One of the defining features of CIs is speaker orientation, but this does not differentiate them from at-issue content: Potts claims that if a speaker utters e.g. Ed fled, this clause will be interpreted as speaker-oriented, since the speaker is the only available agent to which the content of the utterance can be attributed (see p.77, p.213). Another feature that CIs and at-issue content have in common according to Potts is non-deniability: Since CIs are entailed by the utterances that give rise to them, contradiction arises if the same speaker follows an utterance by denying either its CI content or its at-issue content. This is illustrated in (4.44a) (p.111), where the CI that Edna is a fearless leader cannot be denied, on pain of contradiction, parallel to the nondeniability of the at-issue content shown in (19):

(4.44a) Edna, a fearless leader, started the descent. \#Edna is not a fearless leader.

(19) Edna, a fearless leader, started the descent. \#Edna didn’t start the descent.

In keeping with these similarities, Potts presents it as a virtue of the rule of parsetree interpretation that both the at-issue content at the root node and the CI content at other nodes are interpreted in the same manner, namely "as though they had main clause force" (p. 147). We might say, then, that CIs always "project", but in other respects are just like at-issue content. But this overlooks a crucial difference between CIs and at-issue content: After an utterance containing a CI, another interlocutor in reply can only straightforwardly deny the at-issue content, not the CI. Consider (20):

(20) A: Edna, a fearless leader, started the descent.

B: No, that's not true. 
B's reply can only be interpreted as denying the at-issue content, 'No, Edna has not started the descent; in fact, I just saw Edna on the top of the mountain.' As with a presupposition, B cannot take issue with the CI contributed by the supplement without some sort of metalinguistic comment or interruption to the flow of conversation, the sort of thing illustrated by Shannon's (1976) Hey, wait a minute! test (von Fintel 2004, Roberts to appear):

A: Edna, a fearless leader, started the descent.

B: Hey, wait a minute! - Edna is not a fearless leader. She's a coward!

Correspondingly, in a yes/no question like (22) the question is whether Edna has started the descent, not whether Edna is a fearless leader:
A: Has Edna, a fearless leader, started the descent?
B: Yes (she has started)./No (she hasn't started).
B': \#Yes, she's fearless./\#No, she's not fearless.

We believe that this is related to an important distinction between Potts' examples with nominal appositives in (4.115) (p.137):

(4.115)a. A former linguist, Edward Witten, is now the top-dog in string theory.

b. Edward Witten, a former linguist, is now the top-dog in string theory.

Although it is certainly the case that the NP a former linguist has the same model-theoretic content in both sentences, intuitively in (a) and (b) there is a difference in the role of the NP in the information structure of the discourse at the time of utterance. Whereas in (a) the speaker is talking about a certain linguist, in (b) the sentence is about Edward Witten. In the latter case, the CI content, the proposition that Witten is a former linguist, is a comment on the main assertion. Only the at-issue content needs to be Relevant to the question under discussion (Roberts 1996b). Hence, (b) would be a felicitous answer to the question Who is Edward Witten?, but (a) would not. Of course, this is not a semantic, but a pragmatic distinction.

To develop an explanatory theory of conventional implicature, it does not suffice to model how CIs are conventionally triggered and contribute to building a semantic interpretation for the sentence. Even though the semantics is multidimensional, in that a distinguished set of types are restricted in their semantic interaction with other types, in the end both CI-types and at-issue types simply contribute entailed propositions. At that point, there is nothing to distinguish them semantically. So why do languages distinguish them? Why do we need CI content, calculated independently from but simultaneously with at-issue content, when both contribute exactly the same kind of information to the Common Ground?

We hypothesize that the answer lies in the presumed relationship of the CI-containing utterance to the context in which it occurs. The very name of the complementary meaning type at-issue meaning suggests as much-presumably, CIs are not at-issue, whatever that means. Generalizing what we observed for (4.115), here's a stab:

The felicity of an utterance necessitates that its at-issue content be relevant to the question under discussion. 
The notion of relevance we have in mind is that of Roberts (1996b), wherein in order to be relevant to the question under discussion, an utterance must contextually entail at least a partial answer to that question. ${ }^{14}$

CIs, on the other hand, tend to contribute information that is not relevant in this waypropositional content in the case of supplemental CIs, information about the speaker's relationship to the at-issue content in the case of expressives. CIs may be relevant to that question but needn't be, and they often seem to be asides or interesting but thematically inessential comments on the atissue content. Surely something like this is part of the explanation for what a conventional implicature is and why we have them.

Against the background of this hypothesis, we turn now to briefly explore one of the central characteristics which Potts claims characterize CI content, speaker-orientation.

\section{$\underline{3.3}$ Speaker-orientation}

Speaker-orientation is actually modeled in at least three different ways within Potts' system:

(i) for regular CIs, via the mechanism involving a speaker-index and the function [insert barred-h here] from speakers to intensional models, as discussed in section 2 above in connection with the rule for interpreting Discourse Structures (3.60);

(ii) in the case of direct quotations, via the semantics of quotation and the lexical entry for utter, as illustrated in (2) and (3) in section 2; and

(iii) for use with utterance modifiers like frankly (where we also find utter again), via the introduction of an overt argument 'the-speaker' for assertions and 'the-addressee' for questions (cf. pp.148-151)

Thus, there is no unified formal treatment of speaker-orientation in this theory. So what does Potts mean by claiming (see his section 2.5) that speaker-orientation is a central defining feature of CIs?

In this section, we want to argue that the speaker-orientation of CIs is directly related to another property that Potts takes to be a defining characteristic of the class of CIs: what he calls their "scopelessness". We would maintain that both phenomena are reflexes of a species of indexicality: CIs are generally anchored to the point of view of the speaker. Hence like English $I$, they do not typically take narrow scope under attitude predicates. But some indexicals can at times be anchored to a situation other than the situation of utterance, as we see in indirect free style $^{15}$ with now or here but not with $I$. When that is the case, they are not "scopeless". In the

\footnotetext{
${ }^{14}$ Note that on Roberts' characterization, an indirect answer may still be relevant in the right context, and overinformative answers are also, nonetheless, entirely relevant. Similarly, a reviewer worries about pronominal adjectives that are intuitively not directly relevant but still at-issue. But since relevance is based on entailment, one cannot judge the relevance of an utterance by that of its parts, but only by the entailments of the whole, and in this regard such adjectives are no more troubling than other kinds of over-informative answers.

${ }^{15}$ This is a literary style wherein the author reports from the perspective of one of her characters, using here, now and some other indexical expressions as anchored to that perspective, but refers to that character in third person. See Banfield (1982) for a characterization.
} 
same way, some CIs can in certain contexts be anchored to a point of view other than that of the speaker. Then they are neither speaker-oriented nor scopeless.

Speaker orientation is intuitively displayed by many of the elements Potts includes as CI triggers, including both expressives and supplements. But the only empirical evidence he gives for the claim that it is an unvarying property involves examples where CIs in the complements of propositional attitude verbs cannot be taken to reflect the attitude of the matrix subject, but must instead reflect the speaker's comment on the at-issue content. This is illustrated by examples like his (4.60) (p.117) and (4.130b) (p.141):

(4.60) Sheila believes that Chuck, a confirmed psychopath, should be locked up. \#But Chuck isn't a confirmed psychopath.

(4.130)a. Motorola said that it is amazing that it has no spare modems.

b. Motorola said that, amazingly, it has no spare modems.

In (4.60), the speaker cannot contradict the embedded supplemental nominal appositive, on pain of contradiction; a confirmed psychopath is the speaker's comment on the referent of Chuck and not a report about Sheila's belief (though it may be implicated that Sheila would agree, in this case). (4.130b), with embedded speaker-oriented adverb amazingly, does not attribute amazement about the lack of spare modems to Motorola's representatives, unlike (4.130a) with the corresponding adjective used predicatively.

Things are a bit different in the case of the honorifics, since with these, as discussed in Potts \& Kawahara (2004), what is expressed does not have propositional content. But they still essentially involve a (non-propositional) attitude on the part of the speaker toward the entity being (anti-) honored.

Hence, in general (p.31) "a CI is never relativized to the beliefs of an entity other than the speaker. But at-issue content certainly can be. So in Sue wrongly believes Conner got promoted, the atissue proposition that Conner got promoted is asserted to hold only in Sue's belief worlds.” Potts compares this to an utterance with a speaker-oriented epithet like that jerk in place of Conner, which attributes nothing to Sue.

Of course, Grice did not claim that CIs are speaker-oriented, and his examples of CIs, but and therefore, do not display this property when embedded. As noted earlier, Potts agrees with Bach (1999) that but and therefore are not, in fact, CIs, and about Grice's failure to discuss the issue of speaker-orientation he says (p.213): “Grice overlooked this property because he almost never investigated embedded examples. ... In general, he used only monoclausal utterances, which tend to make everything speaker-oriented simply because they do not supply any other agent to whom the content might be attributed.”

Besides the speaker-oriented adverbs, Potts discusses another class of supplemental adverbs, those like thoughtfully. He argues that these are "topic-oriented", i.e. comments on the discourse topic, and not always on the subject, as has been claimed. This is illustrated in his example (2.15) (p.14), repeated from above: 
'Physically, the keyboard is smaller than I expected, and extremely well built- - there's no creaking or flexing. The keys look as if they will last well—including their paint. Thoughtfully, there is a clip-on cover for the connector while not in use.'

In (2.15) it seems that the speaker intends us to understand that she believes that in adding a clipon cover, the (here unmentioned) designers of the keyboard were considerate of the user. Potts appears to assume (see p.143) that among the topic-oriented adverbs are Stump's Free Adjuncts (though Stump (1985) doesn’t call them such), as in an example he cites (p.143):

(4.134) [The narrator is describing his time in the Visalia County, CA, jail.] After more than a month in jail, my mother posted bond, bless her soul. ${ }^{16}$

Like the speaker-oriented adverbs, thoughtfully and other topic-oriented adverbs are claimed to always express a judgment on the part of the speaker about the fact corresponding to the main clause to which they're adjoined. But we find it difficult to give a speaker-oriented interpretation to embedded topic-oriented adverbs:

My dad thinks I'm in college. He thinks that(,) after more than a month in jail, my mom just came to visit me on Parents' Weekend.

The speaker of (23) seems to contradict himself, asserting both that his father believes he is in college and that his father believes that the speaker had been more than a month in jail when visited by his mother. ${ }^{17}$ One might conclude that Potts was hasty in taking free adjuncts to be topic-oriented adverbial CIs. But thoughtfully, as well, isn't clearly speaker-oriented by Potts' embedding test:

(24) Joan loves her new keyboard. She tells me that, thoughtfully, there is a clip-on cover for the connector while not in use.

In (24), it seems that it is Joan, and not necessarily the speaker, who thinks the keyboard's designers were thoughtful. In this case, one might argue that the speaker is agreeing with Joan that this inclusion was thoughtful. But the speaker-oriented interpretation seems to be completely ruled out in (25):

(25) Joan is crazy. She's hallucinating that some geniuses in Silicon Valley have invented a new brain chip that's been installed in her left temporal lobe and permits her to speak any of a number of languages she's never studied. She believes that, thoughtfully, they installed a USB port behind her left ear, so the chip can be updated as new languages are available.

We cannot consistently take the speaker in (25) to be predicating thoughtfulness of the purported geniuses, since the speaker clearly implicates that she doesn't think they exist. Yet the last sentence seems felicitous and consistent, with the underlined adverb taken to indicate Joan's attitude toward the geniuses' provision of a USB port. And things get even worse with (26):

\footnotetext{
${ }^{16}$ This example was culled by Arnold Zwicky (p.c. to Potts) from Aaron Kipnis (1999) Angry Young Men, JosseyBass, San Francisco, p.190.

${ }^{17}$ Or else that his father believes that the speaker's mother paid the visit after she had just spent more than a month in jail! In any case, the free adjunct is taken to suggest something about the father's belief, not the speaker's.
} 
(26) [Corporate purchasing agent:] We paid careful attention to the needs of our users before setting new company standards for laptops, but few employees give us any credit for this. Joan is so cynical that she thinks we were motivated purely by financial considerations, without any concern for the users' convenience and satisfaction. She believes that, thoughtfully, her new laptop has a lightweight battery because that's cheaper, not because it's easier to carry.

Since the context makes it clear that Joan does not think the purchasing agents were thoughtful, the final utterance seems contradictory, despite the fact that it's clear that the speaker does think the laptop weight was a thoughtful choice.

In the face of examples like (24)-(26), Potts might be driven to conclude that the topic-oriented adverbs are not, after all, CIs, while still maintaining that speaker-orientation under embedding is a necessary test for CI-hood. It does seem clear that the other CIs of interest to Potts are speakeroriented in the embedded examples he considers, so there is something behind this claim for the non-topic-oriented CIs.

However, there are contexts in which even non-topic-oriented CIs are not speaker-oriented. E.g., as a follow-up to (25), the non-restrictive, or supplemental relative clause in (27) is taken to report Joan's belief, not the speaker's:

(27) Joan believes that her chip, which she had installed last month, has a twelve year guarantee.

This potential shift from the speaker's judgment to that of another doxastic agent is also possible with expressives. Potts \& Kawahara (2004, section 7) mention that shifting may sometimes occur with these, so that an honorific or wh-expletive like the hell may be taken to indicate attitude on the part of someone other than the speaker. William Taschek (p.c.) noted this possibility with English expressives, as in the following example:

(28) [Context: We know that Bob loves to do yard work and is very proud of his lawn, but also that he has a son Monty who hates to do yard chores. So Bob could say (perhaps in response to his partner's suggestion that Monty be asked to mow the lawn while he is away on business):]

Well, in fact Monty said to me this very morning that he hates to mow the friggin' lawn.

This possibility of shifting from speaker-orientation toward anchoring to another doxastic agent (believer) is, as one might expect, context-dependent, and in general seems to be easier with embedded complements of attitude verbs than in indirect speech. The examples Potts uses tend to be pragmatically biased to preclude the non-speaker-oriented, subject-anchored interpretation, as in this example with a nominal appositive CI (p.117):

(4.60) Sheila believes that Chuck, a psychopath, is fit to watch the kids.

But suppose that it is in the interlocutors' common ground that Chuck is a psychopath. Then consider this report:

(29) Sheila believes that Chuck, a sweetheart if she ever met one, is fit to watch the kids. 
In such a case, one is likely to get the subject-anchored interpretation, where Sheila is committed to Chuck's being a sweetheart, not the speaker.

The possibility of shifting the doxastic ground for some (non-topic-oriented) CIs in some contexts suggests that they involve a species of indexicality: they are indexed to the attitude of some doxastic agent, the default being the speaker. ${ }^{18}$ On this view, Potts' CIs are very much like $I$, now, and here, which are generally indexed to the speaker, speech time and speaker's location.

Kratzer (1999) points out that when certain expressives, epithets like that bastard, occur in reported speech contexts they may "be predicated of the reported situation, rather than the utterance situation":

(30) My father screamed that he would never allow me to marry that bastard Webster.

and argues that they differ in this respect from indexicals, citing the behavior of $\mathrm{I} / \mathrm{me}$ in the same embedded contexts; e.g., in (30), me refers to the speaker, not the father whose speech and attitude toward Webster are being reported. The behavior of the epithet in (30) is parallel to the behavior of the supplemental relative clause CI in (29) above, in a reported belief context-the CI reporting Sheila's attitude toward Chuck still refers to Sheila in the third person. That is, first (and second) person pronouns cannot be shifted, but some of the other canonical indexicals can be, as we see in indirect free style. So compare (27), in the context described, with a past-tense description of Joan's beliefs in (31):

(31) Joan believed that now that she had her chip, she could finally travel without dictionaries.

The adverb now in the complement refers not to the speech time, but to the time of Joan's reflections, but the content is clearly de dicto.

And compare Kratzer's (30) with (32) and (33), with the same behavior of now in (32), and of just and here in (33):

(32) My father screamed that now he would have to disown me.

(33) My father ruminated bitterly on what had just transpired, here in his own house.

The shifted CI examples above, especially Taschek's (28), suggest just the sort of adoption of someone else's point of view that we find in indirect free style. Parallel to the way in which the first person pronoun $I$ cannot be shifted, while other indexicals like now and here can, it seems to be more difficult to shift some of Potts' CIs than others; for example, we haven't yet found a good example with an as-parenthetical. And preliminary evidence suggests that the German Konjunktiv I may be unshiftable, as well; see Potts' discussion in his section 5.7.

One important consequence that follows from an indexical view of Potts' CIs generally is this: According to Potts, a central feature of CIs is that they are scopeless, never displaying narrow scope relative to at-issue content. In examples which are doxastically indexed to the speaker (as

\footnotetext{
${ }^{18}$ Again, with the expressives, the attitude in question is arguably non-propositional. Hence, the claim that CIs are indexically anchored to the doxastic ground of some agent may be too narrow; but it will serve for discussion.
} 
opposed to those anchored to another agent, like (24)-(26) above), ${ }^{19}$ the scopelessness follows, without stipulation as an independent property. Note the parallel between the scopelessness of Potts' CIs and the behavior of $I$ :

When I dressed in old clothes, even though I'm one of her best friends, Mary believed that I was a strange beggar.

As discussed at length by Kaplan (1979), the semantic character of $I$ in the complement to believe - the fact that it picks out the speaker-has no place in Mary's belief as reported in (34). It is merely a way to pick out the individual of whom, under an unfamiliar guise, Mary had the reported belief. In other words, an indexical which is not doxastically anchored to the subject of the attitude verb (as now can sometimes be, in indirect free style) can only be anchored to the speaker's circumstances at the time of utterance. Since in the canonical cases, Potts' CIs are doxastically anchored to the speaker, they are similarly not susceptible to narrow scope interpretation.

However, in the cases where CIs are anchored to an agent other than the speaker, they do appear to take narrow scope relative to the embedding attitude predicate (or implicit point of view, as (28)). This argues that CIs aren't actually scopeless in the sense that Potts intends. Rather, the apparent scopelessness in the speaker-oriented cases is due to their indexicality. To provide a full argument for this parallel would take us well beyond the present discussion. The point here is that it would seem to be most accurate and general to claim that the CIs which Potts considers are anchored to the agent whose point of view is salient at the time of utterance. Normally, the default point of view will be that of the speaker. But in indirect free style, it can be that of another agent. ${ }^{20}$

Moreover, the sense in which the CIs discussed in this section are scopeless pertains solely to their interpretation with respect to a propositional attitude. As we will see in the following section, where the attitudes are not concerned, CIs certainly can take narrow scope with respect to other, non-propositional operators.

\subsection{CIs and presupposition projection}

At several points in the book, Potts makes it clear that the independence of CI content from atissue content is a central defining feature of CIs in his theory:

....as the term 'multidimensional' is used in the present work, this is not a new property, but rather an implementation of the independence property that arguably forms the backbone of the definition [of Conventional Implicature]. (p. 42)

\footnotetext{
${ }^{19}$ Doxastic anchoring to an agent is a loose notion, intended to suggest that belief in the truth of the proposition expressed is being attributed to that agent.

${ }^{20}$ A reviewer points out that some of the examples we have given where a clear CI is not speaker-oriented include anaphora to the entity whose viewpoint is intended, and wonders whether this is significant. However, we think that is not essential. The examples in question are (27) and (29), and we find the following variants, without anaphora to the subjects, to work as well:
}

(27') Joan believes that her chip, which was installed last month, has a twelve year guarantee.

$\left(29^{\prime}\right) \quad$ Sheila believes that Chuck, a sweetheart if ever there was one, is fit to watch the kids. 
He argues that a satisfactory account of CIs must capture this independence, and that a virtue of his system is that it provides a compositional procedure that allows for the independent calculation of the at-issue and the CI content, with tight, syntactic restrictions on their interaction (e.g. the fact that at-issue content never takes an argument of CI type). In this respect, his logic provides an implementation for the multidimensionality of meaning noted early on by Jackendoff (1972) and Bellert (1977). As Bellert puts it, when analyzing the semantics of subject-oriented adverbs, "we have here two propositions asserted in one sentence” (Bellert 1977:340).

One place where this independence seems most evident is in the impossibility of binding across the two kinds of content. In this connection, Potts argues (section 3.10) that the well-known “Binding Problem” for Karttunen and Peters' (1979) two-dimensional semantics actually proves to be an advantage for his theory. For example, the fact that it is impossible to bind a variable into an as-parenthetical, illustrated by the unacceptable pronoun he in (3.67) below, simply follows from his type-theoretical distinction, which does not permit binding across dimensions:

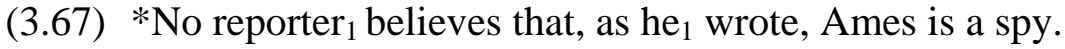

Furthermore, Potts argues that the impossibility of binding across dimensions can also be observed with the other types of supplements, like supplementary relatives:

(3.69) $*$ No reporter ${ }_{1}$ believes that Ames is a spy, which he e $_{i}$ wrote in his column.

(3.70) $*$ No reporter ${ }_{1}$ believes that Ames, often the subject of his ${ }_{1}$ columns, is a spy.

However, he does not note that discourse anaphora from the CI content to the at-issue content seems entirely natural as shown by (4.24') (a variant of his (4.24)), as does discourse anaphora from at-issue to CI content, illustrated by (4.76') (a variant of his (4.76)):

(4.24') Stan Bronowski, who took an exam, passed it with flying colors.

$\left(4.76^{\prime}\right)$ Several students, most of them linguists, missed the bus.

By discourse anaphora, we mean here anaphora that does not involve binding, including but not limited to so-called E-type anaphora. We take it to be the same kind of anaphora that lends pronouns their intended interpretation cross-sententially, as in:

(4.24") Stan Bronowski took an exam. He passed it with flying colors.

$\left(4.76^{\prime \prime}\right)$ Several students missed the bus. Most of them were linguists.

Roberts (2004) argues that generalized quantifiers with existential entailments, like several students, can generally license discourse anaphora to the entailed entity, e.g. in (4.76') and (4.76") the set of students who missed the bus. Hence, it is not that several students either binds or is coreferential with them, but that its existential entailment makes weakly familiar a discourse referent, which latter satisfies the familiarity presupposition which her account posits for the pronoun.

We can also construct such discourse anaphoric relations under a higher operator, as in (35), with anaphora from at-issue to CI content, and (36), with anaphora from CI to at-issue: 
Every professional man I polled said that while his wife, who had earned a bachelor's degree, nevertheless had no work experience, he thought she could use it to get a good job if she needed one.

In each class, several students failed the midterm exam, which they had to retake later.

We can naturally understand (36) to mean that there are both different students and different exams for each class, so that several students and the midterm exam have relational interpretations: 'several students in $x$ ' and 'the midterm exam for $x$ ' for some class $x$ in the domain of each. Hence, the non-restrictive relative clause which they had to retake later-a supplemental CI in Potts' terms-must take narrow scope under the universal each class, even though it is arguably "speaker-oriented" in the sense that the speaker is committed to its truth. The same is true of who had earned a bachelor's degree in (35), by virtue of the fact that there are presumably different degrees for (the wives of) different professional men.

These examples present a serious empirical problem for Potts' account. He predicts that except for the content of the CI trigger's argument, the propositional content of the CIs in (35) and (36) is calculated entirely independently of the at-issue content. So in (36), CommA takes they had to retake x later to yield the CI content on one node of a parsetree in $L_{C I}$, that CI-formula in turn contributing an independent proposition to the meaning of the whole via parsetree interpretation. But this simply does not work in this type of example, because in the understood interpretation both students and exam are understood relative to the quantificational at-issue content in each class. I.e., the CI content here has essentially narrow scope with respect to the at-issue content.

Note that (35) and (36) are not counterexamples to the claim that there is no binding across CI and at-issue content. Examples like (3.69) and (3.70), and many others like them involving a variety of CI triggers, seem to show that that claim is true. Discourse anaphora need not involve binding, and in fact, if we are to capture the clause-boundedness of operators, it should not do so. ${ }^{21}$ What the anaphoric examples do argue is that CI content is not logically independent of at-issue content in the way that Potts predicts.

Hence, while it does not seem possible to directly quantificationally bind across the two dimensions, there is evidence that discourse referents introduced in one dimension are available to the interpretation of the other, even locally under the scope of a higher operator. Hence, the independence of CI content from at-issue content in Potts' account, which he argues to be a virtue, actually gives rise to a counterpart of Karttunen \& Peters’ binding problem.

We can see this type of interaction not only in discourse anaphora, but in other types of presuppositional dependence, as well. ${ }^{22}$ Consider:

(37) John, who has two motorcycles, wants his wife to get one too.

(38) It seems like every time I turn around, my neighbor with a motorcycle is dating a different woman, who always has one too.

\footnotetext{
${ }^{21}$ The work of Roberts and many others on modal subordination can be viewed as an extended argument to this effect. See Roberts (1989, 1996a) and more recent work by van Rooij (2005), among many other authors on the subject.

${ }^{22}$ A reviewer brought to our attention that a similar observation was made by Wang, Reese \& McCready (2005), who show that presuppositions in nominal appositives need not project out of intensional contexts like conditional ifclauses.
} 
The presupposition triggered by too in (37) is satisfied by an entailment of the supplemental relative clause - that John has a motorcycle. In (38), a presupposition in the supplemental relative clause of the direct object is satisfied by an entailment of the (at-issue) subject, but the object itself takes narrow scope relative to every time I turn around. We could construct examples with a variety of other types of presupposition triggers, as well. Since on Potts' account the supplemental relative does not interact semantically with the at-issue main clause of (38) except to take $a$ different woman as an argument, there is no way to explain the presupposition satisfaction evident here as a function of the usual type of presupposition projection in the compositional semantics. Even intra-sentential presupposition satisfaction can be essentially pragmatic, as argued extensively by Kadmon (2001) and (on one understanding of their theory) van der Sandt (1992) and Geurts $(1996,1999)$. The fact that this takes place across at-issue and CI content under the scope of an operator, as in (35), (36) and (38), shows that this type of pragmatic interaction between the two types of content is essential to their calculation.

Of course, Potts' theory has nothing to say about how such cases of inter-dimensional presupposition-satisfaction arise, because his is a static theory of interpretation, not attempting to calculate how information obtained in the course of interpretation might change the context as the interpretation proceeds. These examples show that such dynamic interaction has to be taken into account in order to satisfactorily explain how CIs work and how they relate to other facets of the conventionally conveyed meaning of an utterance. But this, of course, is a question of their pragmatics.

\section{Conclusion: Multidimensionality and Explanation}

In section 3, we concluded that Potts' CIs display the following properties, more or less in keeping with his characterization:

- CIs are not at-issue content. We have suggested a more substantive, pragmatic characterization of at-issueness in section 3.2, from which it follows that non-at-issue content like that of CIs need not address the question under discussion.

- CIs often reflect the speaker's point of view on at-issue content. But we argued in section 3.3 that this is just the most common instance of a more general characteristic: They are sensitive to something like point of view, which in the default case is the speaker's orientation toward the issue under discussion/what is said. We suggested that this might be a species of indexicality, and moreover the source of the apparent scopelessness of CIs in many (but not all) constructions.

- CIs are semantically independent from at-issue content, in the sense that the only direct semantic interaction is through function/argument application of the CI functor to its at-issue argument. However, as we saw in section 3.4, this needn't yield an independent proposition, since there may be presuppositions in the content of either CI or at-issue content that can be satisfied only locally (under the scope of an operator in the at-issue content), via information contributed to that local context via the other type of content. Hence, the two kinds of content crucially interact pragmatically in the course of interpretation to yield the attested propositions expressed. 
The discussion in section 3.1 of the performative uses of utterance-modifiers, as well as the point made in section 2 that there is no conventional distinction between at-issue and CI uses of many of the triggering expressions (e.g., those for which Potts uses COMMA) suggests that often the distinction in use is pragmatic rather than syntactico-lexical.

There is another sense in which the CIs discussed by Potts form a class, which is that they all might be characterized as commentaries on the material that the CI-functor takes as argument. But what that argument denotes, and hence what is commented on, differs among the different types of CI functors. A CI may be a commentary on:

a) the at-issue content, or semantic denotation of the argument constituent (most supplemental CIs, many expressives),

b) the speech act performed by the utterance of the argument constituent (utterancemodifiers),

or

c) the speech situation in which the argument takes place (honorifics).

Given all this, two questions about Potts’ account of CIs strike us as important:

1. To what extent is it insightful and/or essential to an adequate explanation of CIs to posit the existence of two separate meaning dimensions?

2. To what extent does such an account make essential use of a representational meaninglanguage, like Potts’ multidimensional $L_{C I}$ trees?

Consider first the question of semantic multidimensionality. Potts repeatedly attempts to justify the naturalness of his multidimensional framework with appeal to accounts of unrelated phenomena which also use multiple dimensions, including Karttunen \& Peters' (1979) account of presupposition projection, and approaches to the interpretive consequences of prosodic Focus like that of Rooth $(1986,1992)$. However, while both of these kinds of proposals have been influential and have made significant contributions to our understanding of the relevant phenomena, it is by no means the consensus opinion that they are successful. Karttunen \& Peters has been broadly criticized, and most approaches to presupposition today use instead a dynamic approach to interpretation, wherein the presuppositional content of an utterance puts constraints on felicitous contexts of utterance, while proffered content adds information to that context (Heim 1983; Geurts 1996, 1999). One might take the dynamic approach to be multidimensional in the sense that any given expression might serve simultaneously to trigger presuppositions, hence to put constraints on prior context, and to contribute to proffered content, hence to update context. But there is no multidimensional semantics in such frameworks. Similarly, Roberts (1996b, in progress), Schwarzschild (1999), and Kadmon (2000) all argue that Rooth's multidimensionality is unnecessary if we understand the presuppositional nature of prosodic focus (which is treated quite differently in their different counter-proposals). In these proposals, again, what was taken as an argument for multiple dimensions is claimed to be instead an argument that prosodic focus constrains felicitous context of utterance. Hence, it has been argued that both multidimensional proposals Potts appeals should be replaced by a suitable account of presupposition within a dynamic theory of interpretation. ${ }^{23}$

${ }^{23}$ Cf. Kamp (1981), Heim (1982), Groenendijk \& Stokhof (1990), Roberts (1996b). Of these, only the Discourse Representation Theory stemming from Kamp's work is representational, so the following sketch suggests the possibility of a non-representational theory of CIs. 
In this vein, consider how one might approach the analysis of CIs, taken to have the properties outlined at the beginning of this section, in a dynamic theory of interpretation. ${ }^{24}$ As in other types of complex sentence, the relevant utterances would contribute to the update of context during the course of their interpretation, contrasting with the static treatment of interpretation in Potts' theory, where the propositions expressed are added to the common ground all at once at the end of interpretation in a meaning-language. As in the static theory, in dynamic interpretation, the arguments of CIs would make two contributions to the on-going update, to both at-issue content and CI content, so that interpretation would not be resource-sensitive. As a CI was calculated dynamically, it also would contribute directly to the local context (e.g. under the scope of a higher operator, as in (35) and (36) in the previous section); however, a CI is anchored to the point of view of the speaker (or some other presupposed doxastic agent), and via this presupposition might seem to take wide scope relative to other attitude predicates. In any case, a CI is always taken to be a commentary by the anchoring doxastic agent on its at-issue argument. There would be no need to maintain a representation of that contribution, once calculated, as the CI has nothing further to add to the semantic composition of the at-issue content. As usual in dynamic interpretation, as at-issue content was calculated, its contributions to local context update could license anaphoric expressions and other presuppositions in whatever may follow, including in subsequent CIs. But the same would be true of CIs: Once a CI was added to the context, just like an initial subordinate clause or other sentential adverbial (Kamp 1981, Heim 1982, Stump 1985), its content could serve to license discourse anaphora in subsequent at-issue content. Such an approach could help to make sense, e.g., of the way that discourse anaphora works dynamically under the scope of higher operators in the examples in section 3.4. On such an approach, the two kinds of content would be functionally distinct from the point of view of the Information Structure of the discourse: Only the at-issue content would be constrained to address the question under discussion in order to satisfy the requirement that the utterance be Relevant.

Of course, this brief sketch of a dynamic theory fails to be a full theory, and is only intended to suggest what strikes us as a promising approach. Whether such an account was viewed as multidimensional would depend on how it was implemented. Clearly a dynamic account would fail to reflect the static independence of the two dimensions stressed by Potts. But a dynamic account might still use distinct types for the two kinds of functors, at-issue and CI. If multidimensionality consisted in that type distinction, one could argue that such an account was still multidimensional. However, as we discussed in earlier sections, it isn't entirely clear what Potts means by claiming that his account is multidimensional. His CIs are contributed both via the types superscripted with $c$ in $L_{C I}$, and via the contributions of utterance-modifier CI-triggers in $L_{U}$. Insofar as CIs are supposed to constitute a single, independent dimension of meaning, as his taxonomic Figure 2.1 (in section 2 above) suggests, then that is not captured by the type distinction even in his theory, but, arguably, by the way in which CIs serve functionally as nonpresuppositional, non-at-issue commentaries on at-issue content.

Then consider the second question we posed above, of whether an adequate account of CIs must make essential use of a representational meaning-language. Potts' $L_{C I}$ trees do capture statically the entailments that arise from CIs apart from presupposition satisfaction. But barring proof that a dynamic account along the lines we have sketched is not possible, it seems premature to argue

\footnotetext{
${ }^{24}$ For an approach that points in the same direction, using SDRT to model the semantic and pragmatic properties of Japanese CI trigger yoku(mo), see McCready (2004).
} 
that a representational meaning-language is necessary. And we have argued that it is not sufficient.

In fact, in all the respects in which we have argued, in section 3, that Potts' theory is inadequate to explain features of CIs, a dynamic theory like the one just sketched would seem more promising, precisely because dynamic theories are designed to model the interaction of syntactically-driven compositional semantics with contextually-enriched pragmatics in the course of interpretation. This is obvious in the case of presupposition satisfaction and anaphora, for which dynamic theories were first proposed. But also we argued in section 3.2 that the functional distinction between at-issue and CI content is a question of how the two different types of content contribute to the Information Structure of the discourse, with only the at-issue constrained to address the question under discussion.

None of this is to detract from Potts' achievement in promoting recognition of a class of meanings heretofore neglected, and in exploring some of their essential syntactic and semantic properties. Especially, we appreciate the detailed, formal nature of his proposal, which contributes significantly to our ability to explore the ramifications of his thesis. However, if we are to take seriously his claim to have provided an explanatory theory of CIs, we must consider what this would mean. Consider Lewis' (1970) famous dictum: ${ }^{25}$

In order to say what meaning is, we may first ask what a meaning does, and then find something that does that.

If we do find a way to model some linguistic phenomenon that accurately predicts how it will behave in actual speech, have we hereby given an explanatorily adequate account of that phenomenon? Chomsky has repeatedly made a distinction between descriptive and explanatory adequacy:

A genuine theory of human language has to satisfy two conditions: "descriptive adequacy" and "explanatory adequacy." The grammar of a particular language satisfies the condition of descriptive adequacy insofar as it gives a full and accurate account of the properties of the language, of what the speaker of the language knows. To satisfy the condition of explanatory adequacy, a theory of language must show how each particular language can be derived from a uniform initial state under the "boundary conditions" set by experience. In this way, it provides an explanation of the properties of languages at a deeper level.

(Chomsky 2000:7)

In the light of Chomsky’s distinction, Lewis’ advice might appear to suggest a way of modeling “a full and accurate account of what the speaker of the language knows” in using a conventional meaning-bearing unit of that language, i.e. of how to develop a descriptively adequate theory of the phenomenon in question. One might question whether modeling the conventional contribution to what is entailed by the CI-content of an utterance, while it follows Lewis' valuable advice in capturing some of the semantic characteristics of CIs and thereby provides insight into the phenomenon in question, even satisfies Chomsky's descriptive adequacy, because it fails to help us understand the pragmatic dimensions of these contributions to meaning.

${ }^{25}$ On p.173 of the 1972 reprinting. 
An explanatory theory will be harder still to come by. For it will involve not only understanding how CIs work in one language, but across the range of human languages. Do other languages besides English and German (with its Konjunktiv I) and Japanese (with its honorifics) even have CIs? Surely some do, but is this a universally realized category of meaning? (Compare other pragmatic phenomena: It seems that focus is a (?near-)universally realized phenomenon.) If CIs are not universal, why not? Perhaps even more important: If so, why so? Will it turn out that CIs arise cross-linguistically in a way that is non-detachable in the sense of Grice (1967), and hence essentially tied to the lexical semantics of the triggers in question? If so, that would seem to argue that qua CI-triggers they aren't conventional (in the sense of Lewis 1969). We conjecture that the answers to these questions will require us to understand how CIs pertain to the context of

utterance. This is an essentially pragmatic question, and Potts (2005), as promised, has nothing to say about that.

\section{References:}

Abbott, B. (2000). Presuppositions as non-assertions. Journal of Pragmatics 32 (10): 1419-1437. Asudeh, A. \& Crouch, R. (2002). Derivational parallelism and ellipsis parallelism. In L. Mikkelsen \& Christopher Potts (Eds.) Proceedings of the $21^{\text {st }}$ West Coast Conference on Formal Linguistics. Somerville, MA: Cascadilla Press, 1-14.

Austin, J.L. (1962). How to Do Things with Words. (Oxford: Clarendon Press)

Bach, K. (1999). The Myth of Conventional Implicature. Linguistics and Philosophy 22:327.

Banfield, A. (1982). Unspeakable Sentences: Narration and representation in the language of fiction. (Boston: Routledge \& Kegan Paul)

Bar-Hillel. (1971). Pragmatics of Natural Language. (Dordrecht: Reidel)

Barker, C. \& Jacobson, P. (2007). Direct Compositionality. (New York: Oxford University Press)

Bellert, I. (1977). On semantic and distributional properties of sentential adverbs. Linguistic Inquiry 8: 227-51.

Boër, S. E. \& Lycan, W. G. (1980). A performadox in truth-conditional semantics. Linguistics and Philosophy 4.1:71-100.

Bonami, O. \& Godard, D. (2005). Evaluative adverbs and underspecified semantic representations. In Frank Richter and Manfred Sailer (Eds.) Proceedings of the ESSLLI Workshop on Empirical Challenges and Analytical Alternatives to Strict Compositionality.

Bonami, O., Godard, D. \& Kampers-Mahne, R. (2004). Adverb classification. In Francis Corblin and Henriëtte de Swart (Eds.) Handbook of French Semantics. (Stanford: CSLI Publications)

Chierchia, G. (1988). Reference to Kinds across Languages. Natural Language Semantics, 6: 339405.

Chomsky, N. (2000). New Horizons in the Study of Language and Mind, Cambridge University Press.

von Fintel, K. (2000). What is presupposition accommodation? Retrieved November 10, 2007, from http://web.mit.edu/fintel/www/accomm.pdf.

von Fintel, K. (2004). Would you believe it? The king of France is back! Presuppositions and truth-value intuitions. In Marga Reimer and Anne Bezuidenhout (Eds.), Descriptions and Beyond, Oxford University Press.

Gazdar, G. (1979). Pragmatics: Implicature, Presupposition, and Logical Form. Academic Press, NY. 
Geurts, B. (1996). Local satisfaction guaranteed: A presupposition theory and its problems. Linguistics and Philosophy 19(3):211-257.

Geurts, B. (1998). The mechanisms of denial. Language 74:274-307.

Geurts, B. (1999). Presuppositions and Pronouns. Elsevier, Amsterdam.

Geurts, B. \& Maier, E. (2005). Quotation in Context. In: Philippe de Brabanter (Ed.) Hybrid Quotations. Benjamins, Amsterdam, 109-128.

Grice, H.P. (1961). The causal theory of perception. Proceedings of the Aristotelian Society, Supplementary Volume, 35:121-52.

Grice, H. P. (1967). Logic and Conversation. William James Lectures, Harvard University. Reprinted in Peter Cole and Jerry Morgan (Eds.) (1975) Syntax and Semantics 3. Academic Press, New York, and in Grice (1989) Studies in the way of words, 22-40. Cambridge, MA: Harvard University Press.

Groenendijk, Jeroen, and Stokhof, Martin. 1990. Dynamic Montague Grammar. In Papers from the Second Symposium on Logic and Language, eds. L. Kálman and L. Pólos, 3-48. Budapest: Adakémiai Kiadó.

Heim, I. (1982). The Semantics of Definite and Indefinite Noun Phrases. Ph.D. dissertation, University of Massachusetts, Amherst.

Heim, I. (1983). On the projection problem for presuppositions. WCCFL 2, Stanford University, 114-126.

Heim, I. (1992). Presupposition Projection and the Semantics of Attitude Verbs. Journal of Semantics 9: 183-221.

Horn, L. R. (1989). A Natural History of Negation. Chicago: University of Chicago Press. Reissued 2001 by CSLI.

Horn, L. R. (1991). Given as new: When redundant affirmation isn’t. Journal of Pragmatics 15:313-36.

Horn, L. R. (2002). Assertoric inertia and NPI licensing. Proceedings of the Annual Meeting of the Chicago Linguistic Society. Volume 38, Part Two: The Panels. University of Chicago.

Jackendoff, R. S. (1972). Semantic Interpretation in Generative Grammar. (Cambridge, MA: MIT Press.)

Kadmon, N. (2000). Some theories of the interpretation of accent placement. Ms., Tel Aviv University. (talk at Colloque de Syntax et Sémantique, Paris 2000)

Kadmon, N. (2001). Formal Pragmatics. (Oxford: Blackwell)

Kamp, H. (1981). A Theory of Truth and Semantic Representation. In Jeroen Groenendijk, Theo M. V. Janssen and Martin Stokhof (Eds.) Formal Methods in the Study of Language, Vol. I, Mathematische Centrum, Amsterdam. Reprinted in Groenendijk, Janssen and Stokhof (Eds.), 1984, Truth, Interpretation and Information, Foris, Dordrecht.

Kamp, H. \& Reyle, U. (1993). From Discourse to Logic: Introduction to Modeltheoretic Semantics of Natural Language, Formal Logic and Discourse Representation Theory. Dordrecht: Kluwer.

Karttunen, L. \& Peters, S. (1979). Conventional implicature. In C.-K. Oh \& D.A. Dineen (Eds.) Syntax and Semantics, Vol. 11, Academic Press, NY.

Kay, P. (1990). Even. Linguistics and Philosophy 13:59-111.

Kratzer, A. (1998). Scope or Pseudoscope? Are there wide-scope indefinites? In Susan Rothstein (Ed.) Events and Grammar. Kluwer, Dordrecht, 163-196.

Kratzer, A. (1999). Beyond Ouch and Oops. How descriptive and expressive meaning interact. Comments on a paper by Kaplan, Cornell Conference on Theories of Context Dependency, March, 1999.

Lakoff, G. (1972). Linguistics and natural logic. In D. Davidson \& G. Harmon (Eds.) Semantics of Natural Language. Dordrecht: Reidel, 545-665. 
Lakoff, G. (1975). Pragmatics in natural logic. In Keenan (Ed.) Formal Semantics of Natural Language. Cambridge University Press, 253-286.

Levinson, S. C. (1985). Pragmatics. Cambridge: Cambridge University Press.

Lewis, D. (1969). Convention, Harvard University Press.

Lewis, D. (1970). General semantics. Synthese 22:18-67. Reprinted in D. Davidson \& Gilbert Harman (Eds.) (1972) Semantics of Natural Language, Reidel, Dordrecht, 169-218.

McCready, E. S. (2004). Two Japanese Adverbials and Expressive Content, in Proceedings of SALT 14, K.Watanabe and R. Young, Eds., CLC, Ithaca, pp. 163-178.

Partee, B. H. (1987). Noun Phrase Interpretation and Type-Shifting Principles. In Jeroen Groenendijk, Dick de Jong, and Martin Stokhof (Eds.), Studies in Discourse Representation Theory and the Theory of Generalized Quantifiers. Dordrecht: Foris Publications, 115-43.

Percus, O. \& Sauerland, U. (2002). Pronoun movement in dream reports. In Makoto Kadowaki \& Shigeto Kawahara (Eds.) (2003) Proceedings of the $33^{\text {rd }}$ North East Linguistics Society Meeting, Amherst, MA, 265-83.

Pollard, C. \& Sag, I. (1994). Head-Driven Phrase Structure Grammar. CSLI Press.

Portner, P. (2005). Instructions for interpretation as separate performatives. Ms., Georgetown University. Available on his website: http://www9.georgetown.edu/faculty/portnerp/.

Potts, C. (2007). The dimensions of quotation. In Chris Barker and Pauline Jacobson, (Eds.) Direct Compositionality, Oxford University Press, 405-431.

Potts, C. (2005). The Logic of Conventional Implicatures. (New York: Oxford University Press)

Potts, C. (2006). The expressive dimension. To appear with invited commentaries in Theoretical Linguistics.

Potts, C. and Kawahara, S. (2004). Japanese honorifics as emotive definite descriptions. In Kazuha Watanabe and Robert B. Young (Eds.) Proceedings of Semantics and Linguistic Theory 14, 235-254. CLC Publications: Ithaca, NY.

Recanati, F. (2001). Open quotation. Mind 110:637-687.

Roberts, C. (1989). Modal subordination and pronominal anaphora in discourse. Linguistics and Philosophy 12(6):683-721.

Roberts, C. (1996a). Anaphora in intensional contexts. In Shalom Lappin (Ed.) The Handbook of Contemporary Semantic Theory, Basil Blackwell.

Roberts, C. (1996b) Information Structure: Towards an integrated formal theory of pragmatics. In Jae Hak Yoon and Andreas Kathol (Eds.) OSUWPL Volume 49: Papers in Semantics, 1996. The Ohio State University Department of Linguistics. Available in updated form on the Semantics Archive.

Roberts, C. (2007). Uniqueness in definite noun phrases. Linguistics and Philosophy 26:287-350.

Roberts, C. (2004). Pronouns as definites. In Marga Reimer \& Anne Bezuidenhout (Eds.) Descriptions and Beyond. Oxford University Press.

Roberts, C. (to appear). Only: Presupposition and implicature. Accepted with revisions by the Journal of Semantics.

Roberts, C. (in progress). Resolving focus. Ms., presented at Sinn und Bedeutung XI, Barcelona, September, 2006.

van Rooij, R. (2005). A modal analysis of presupposition and modal subordination. Journal of Semantics 22(3):281-305

Rooth, M. (1985). Association with Focus. Ph.D. dissertation, University of Massachusetts, Amherst.

Rooth, M. (1992). A theory of focus interpretation. Natural Language Semantics, 1(1):75-116.

Ross, J. R. (1970). On declarative sentences. In R.A. Jacobs \& P.S. Rosenbaum (Eds.) Readings in English Transformational Grammar. Waltham: Ginn, 222-272. 
Sadock, J. M. (1974). Toward a Linguistic Theory of Speech Acts. New York: Academic Press. van der Sandt, R. (1992). Presupposition projection as anaphora resolution. Journal of Semantics 9:333-377.

Sauerland, U. \& Heck, F. (2002). LF-Intervention Effects in Pied-Piping. Handout, NELS 33, MIT.

Schwarzschild, R. (1999). GIvenNess, AvoidF and Other Constraints on the Placement of Accent. Natural Language Semantics 7(2):141-177.

Shannon, B. (1976). On the two kinds of presuppositions in natural language. Foundations of Language 14:247-9.

Simons, M. (2001). On the conversational basis of some presuppositions. Proceedings from Semantics and Linguistic Theory, 2001, 11, 431-448.

Stalnaker, R. C. (1979). Assertion. In Peter Cole (Ed.), Syntax and Semantics 9: Pragmatics. New York: Academic Press, 315-332.

von Stechow, A. (2003). Binding by verbs: Tense, person and mood under attitudes. In Makoto Kadowaki \& Shigeto Kawahara (Eds.) Proccedings of the $33^{\text {rd }}$ North East Linguistics Society Meeting. GLSA, Amherst, MA.

Stump, G. (1985). The Semantic Variability of Absolute Constructions. Kluwer, Dordrecht.

Wang, L., Reese, B. \& McCready, E. (2005). The projection problem of nominal appositives. Snippets 10:13-14. 


\section{Figures from Potts (2005)}

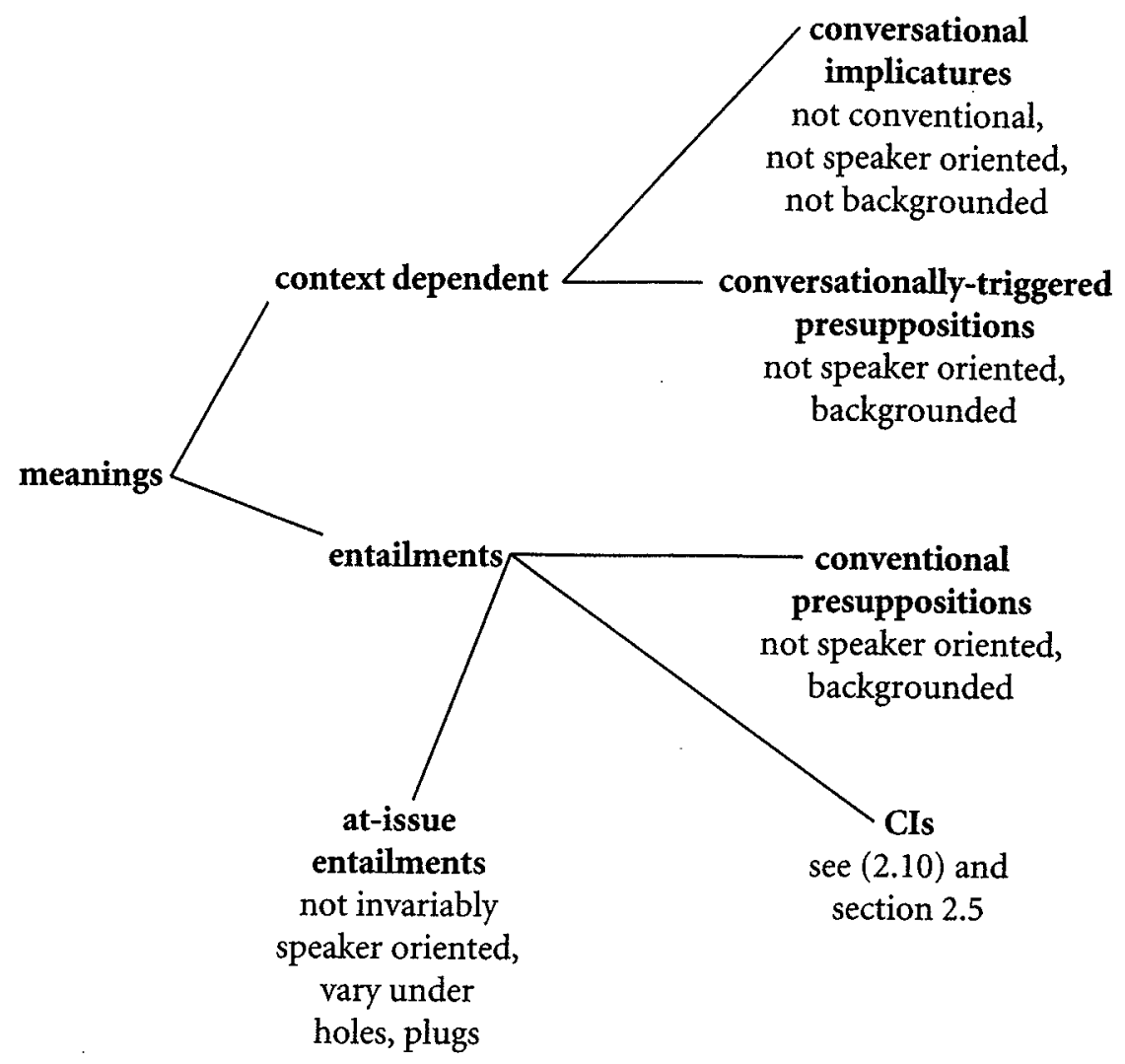

FIGURE 2.1. A Meaning Graph

(3.34) at-issue application

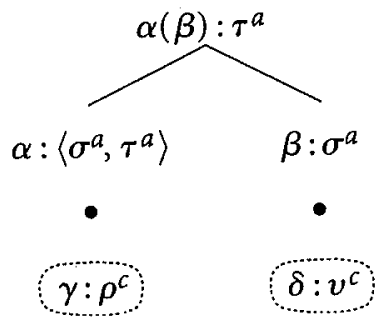

(3.38) CI application

$$
\beta: \sigma^{a}
$$

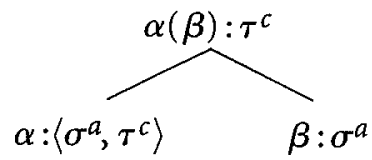

$$
\begin{gathered}
\bullet \\
\gamma: \rho^{c}
\end{gathered}
$$


(3.39)

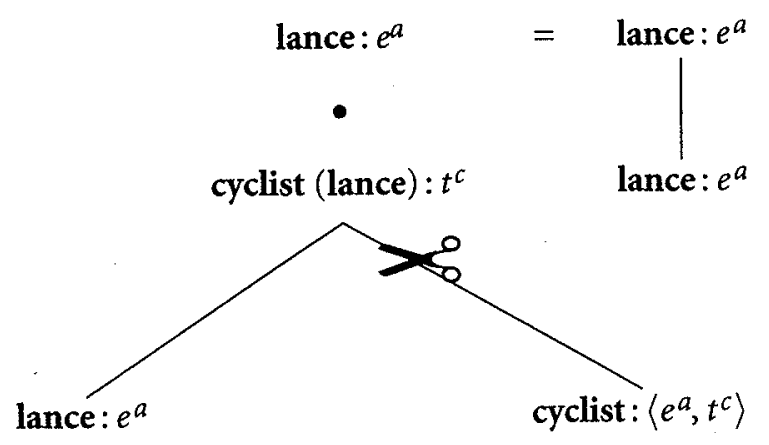

(3.41) isolated CIs

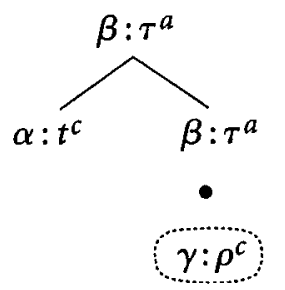

(3.42) feature semantics

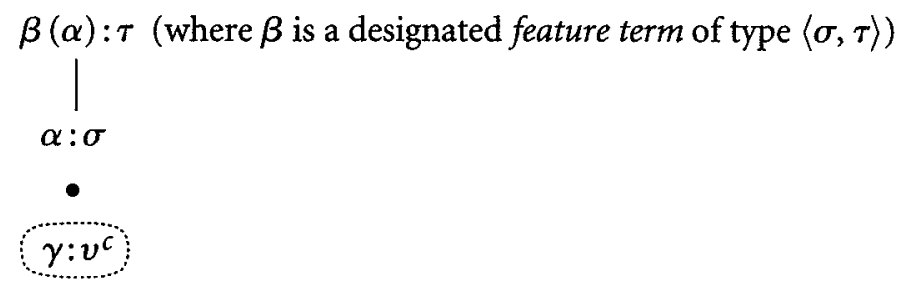

(3.46) parsetree interpretation

Let $\mathcal{T}$ be a semantic parsetree with the at-issue term $\alpha: \sigma^{a}$ on its root node, and distinct terms $\beta_{1}:\left\langle s^{a}, t^{c}\right\rangle, \ldots, \beta_{n}:\left\langle s^{a}, t^{c}\right\rangle$ on nodes in it (extensionally, $\beta_{1}: t^{c}, \ldots, \beta_{n}: t^{c}$ ). Then the interpretation of $\mathcal{T}$ is the tuple

$$
\left.\left\langle\llbracket \alpha: \sigma^{a}\right]^{\mathcal{M}_{i, g}},\left\{\llbracket \beta_{1}:\left\langle s^{a}, t^{c}\right\rangle \rrbracket^{\mathcal{M}_{i}, g}, \ldots, \llbracket \beta_{n}:\left\langle s^{a}, t^{c}\right\rangle \rrbracket^{\mathcal{M}_{i}, g}\right\}\right\rangle
$$

where $\llbracket \cdot \rrbracket^{\mathcal{M}_{i}, g}$ is the interpretation function, taking formulae of the meaning language to the interpreted structure $\mathcal{M}_{i}$, relative to a variable assignment $g$. 
(4.136) a. Thoughtfully, the batteries were included.

$b$. included(the(batteries))( $\left(x_{1}\right)$ :

$$
\left\langle s^{a}, t^{a}\right\rangle
$$

thoughtfully(included(the $($ batteries $\left.))\left(x_{1}\right)\right)\left(x_{1}\right)$ :

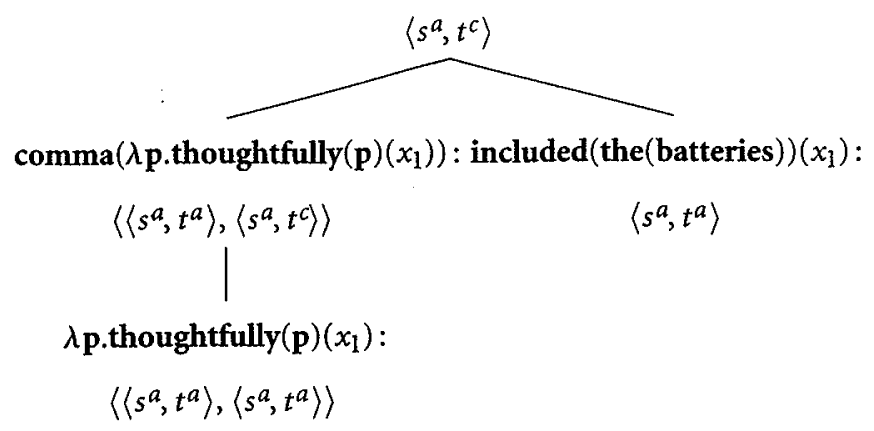




\section{A.2.5 Interpretation for $\mathcal{L}_{\mathrm{CI}}$}

The interpretation function for $\mathcal{L}_{\mathrm{Cl}}$ is given by $\mathbb{I} \cdot \mathbb{J}^{\mathcal{M}} \cdot g$, where $\mathcal{M}_{i}$ is an intensional model and $g$ is a variable assignment: if $x$ is a variable of type $\sigma$, then $g(x) \in D_{\sigma}$.

(A.22) a. $\llbracket \alpha: \sigma \rrbracket^{\mathcal{M}_{i} \cdot g}= \begin{cases}V_{i}(\alpha) & \text { if } \alpha \text { is a constant of } \mathcal{L}_{C I} \\ g(\alpha) & \text { if } \alpha \text { is a variable of } \mathcal{L}_{\mathrm{CI}}\end{cases}$

b. $\llbracket \alpha(\beta): \tau \rrbracket^{\mathcal{M}_{i}, g}=[\alpha:\langle\sigma, \tau\rangle]^{\mathcal{M}_{i} \cdot g}\left(\llbracket \beta: \sigma \rrbracket^{\mathcal{M}_{i} \cdot g}\right)$

c. $\llbracket \lambda x, \alpha:\langle\sigma, \tau\rangle \rrbracket^{\mathcal{M}: g}=$ the $f$ such that $f(\mathrm{~d})=\llbracket \alpha: \tau \rrbracket^{\mathcal{M}, g[x=\mathrm{d}]}$, where $g[x:=\mathbb{d}]$ is an assignment that takes $x$ to $d$ and maps all variables $y$ distinct from $x$ to $g(y)$.

d. $[\neg \alpha]^{\mathcal{M}_{i \cdot g}}=1$ iff $[\alpha]^{\mathcal{M}_{i \cdot g}}=0$

e. $[\alpha \vee \beta]^{\mathcal{M}_{i} g}=1$ iff $\left.\llbracket \alpha\right]^{\mathcal{M}_{i g}}=1$ or $[\beta]^{\mathcal{M}_{i \cdot g}}=1$

f. $\quad \exists x[\alpha]]^{M_{i}, g}=1$ iff there is a $\mathrm{d} \in D_{\sigma}$ such that $[\alpha]^{\mathcal{M}_{i},[x=\mathrm{d}\}}=1$.

g. $[G \times[\alpha]]^{M_{i} g}=1$ iff there are sufficiently many $\mathbb{d} \in D_{\sigma}$ such that $[\alpha]^{M}, g\{x=\mathrm{d}]=1$ to make this appear lawful.

This definition is of course quite partial. It could be fleshed out in many ways. 
(1) L parsetree for Lance, a cyclist, is from Texas'

(where Iisfrom Texas $]$ = from-Texas')

from -Texas (lance): $t^{a}$

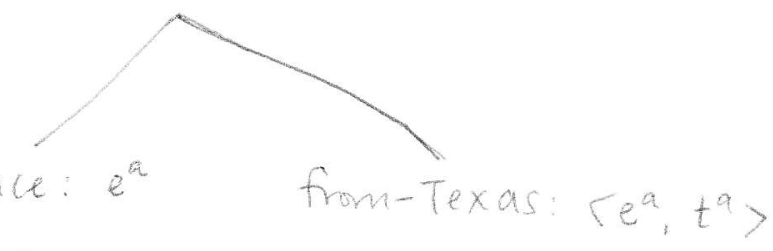

lance: $e^{\text {s }}$

from-Texas: $\left\langle e^{a}, t^{a}\right\rangle$

6

cyclist' (lance): $t^{c}$

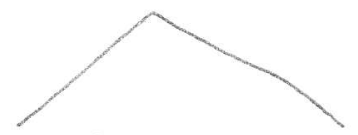

lance: $e^{a} \quad$ cyclist: $\left\langle e^{a}, t^{c}\right\rangle$

(3) Derivation of (2), as spoken by Chris

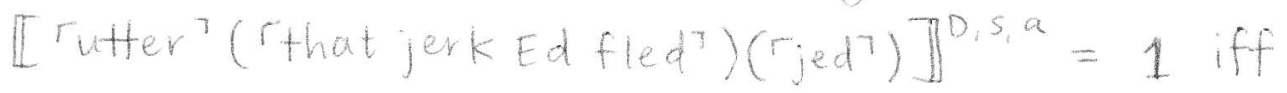
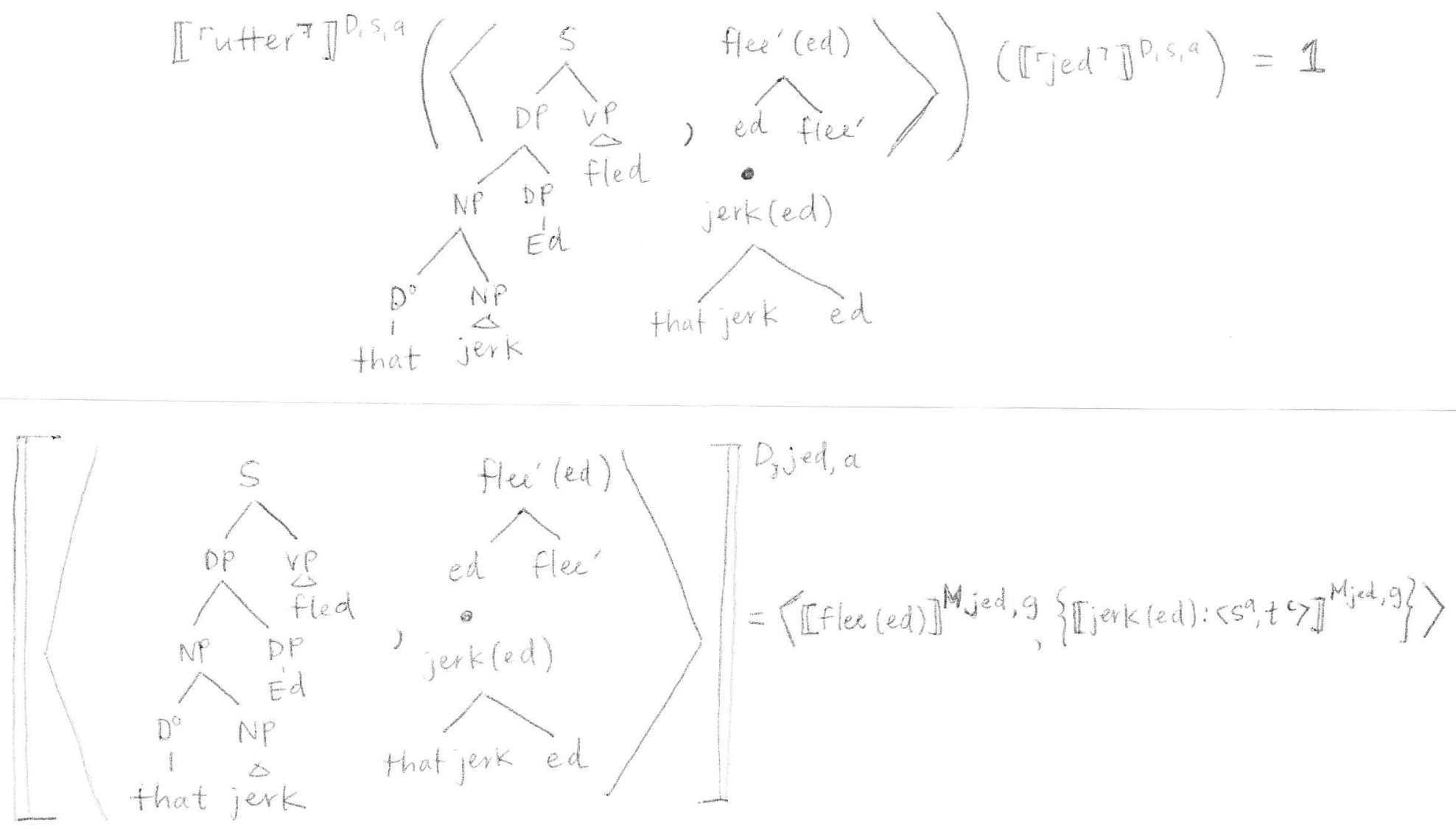

$=1$ iff Ed fled and Ed is a jerk in M jed

The whole sentence $=1 \mathrm{iff}$ in Morris, Jed said that Ed fled, and Ed is a jerk in M Jed 